\title{
Meiotic budding yeast assemble bundled triple helices but not ladders
}

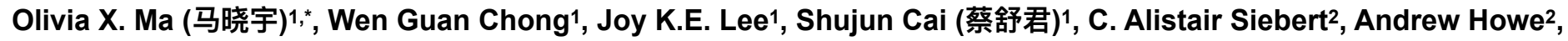 \\ Peijun Zhang2,3, Jian Shi, Uttam Surana ${ }^{4-7}$, and Lu Gan (甘露) ${ }^{1, \infty}$
}

1 Department of Biological Sciences and Centre for Biolmaging Sciences, National University of Singapore, Singapore

2 Diamond Light Source Ltd, Harwell Science \& Innovation Campus, Didcot, Oxfordshire, OX11 ODE

3 Division of Structural Biology, Wellcome Centre for Human Genetics, University of Oxford, Oxford OX3 7BN, UK

4 Institute of Molecular and Cell Biology, Agency for Science, Technology and Research (A*STAR), Proteos, 61 Biopolis Drive, Singapore

5 Bioprocessing Technology Institute, $A^{*}$ STAR, Singapore

6 Biotransformation Innovation Platform, A*STAR, Singapore

7 Department of Pharmacology, National University of Singapore, Singapore

* Present address: Southern University of Science and Technology, Shenzhen, China

Correspondence: lu@anaphase.org

\begin{abstract}
In meiosis, cells undergo two sequential rounds of cell division, termed meiosis I and meiosis II. Textbook models of the meiosis I substage called pachytene show that nuclei have conspicuous 100-nm-wide, ladder-like synaptonemal complexes (SC), which form between homologous chromosomes. It remains unknown if cells have any other large, meiosis-specific nuclear structures. Here we present cryo-ET analysis of frozen-hydrated budding yeast cells before, during, and after pachytene. We found no evidence for the dense ladder-like structures expected of the SC or the ordered chromatin loops expected to project from their sides. Instead, we found large quantities of 12-nm-wide triple-helices that pack into crystalline bundles. These structures are present in meiotic cells, but not in interphase cells, so we call them meiotic triple helices (MTHs). MTHs are enriched in the nucleus but not enriched in the cytoplasm. Bundles of MTHs form at the same time as SCs in wild-type cells and also in mutant cells that are unable to form SCs. These results suggest that in yeast, SCs are not crystalline and that they coexist with large, previously unreported meiotic machines.
\end{abstract}

Keywords: Pachytene, Synaptonemal complex, Cytoskeleton, Cryo-ET

\section{Introduction}

Meiosis is a conserved form of cell division in which diploid cells go through one round of DNA replication followed by two sequential rounds of cell division. The resulting gametes have half the number of parental chromosomes. Homologous chromosomes segregate in the first division (meiosis I) and sister chromatids segregate in the second division (meiosis II). While meiosis II closely resembles mitosis, the form of chromosome segregation in proliferating cells, meiosis I has very different chromosome behaviors. For example, the chromosomes in early meiosis I cells undergo rapid cytoplasmic actin-dependent motions [1] and acquire programmed double-strand breaks [2]. Later in meiosis I, the homologous chromosomes align along their lengths and undergo recombination using machines that are not present in mitosis [3].

The budding yeast Saccharomyces cerevisiae (herein called yeast) uses conserved macromolecular machines to carry out chromosome alignment, homologous recombination, and segregation during meiosis I. Among the meiosis-specific structures, the most iconic one is the SC, a conserved 100-nmwide protein assembly that forms in between homologous chromosomes from end to end [4, 5]. In traditional electronmicroscopy images, the SC presents a ladder-like organization, comprised of two parallel lateral elements (the rails), which are bridged by densely packed rung-like features in the central region $[6,7]$. The central region has at least two subcomponents - the transverse filaments (the rungs), which align perpendicular to the lateral elements, and the central element, which aligns parallel to the lateral elements [8, 9]. Homologous chromosomes are believed to arrange as chromatin loops that anchor at and project from the lateral elements [10]. Despite the low sequence conservation of its component proteins, the SC's structural features are common to most eukaryotes [11-14].

Meiotic nuclei have been studied for decades by traditional EM $[11,12]$, but the 3-D macromolecular organization of meiosisspecific complexes remains unknown in situ because traditional EM has fixation, dehydration, and staining artifacts. Cryo-ET can reveal 3-D nanoscale structural details of cellular structures in a life-like state because the samples are kept unfixed, unstained, and frozen-hydrated during all stages of sample preparation and imaging [15]. We use cryo-ET to visualize the organization of meiotic yeast nuclei throughout meiosis I, focusing on pachytene. The pachytene nuclei lack ladder-like densities and are instead enriched with bundles of MTHs. Time series experiments and chemical perturbations show that these MTHs coincide with the formation of SCs and are sensitive to 1,6-hexanediol and Latrunculin A. MTHs are still present in mutants that cannot form SCs. Our work shows how current models of pachytene nuclear cytology need revision.

\section{Results}

To make the cryo-ET analysis of meiotic cells feasible, we used strains of the SK-1 background [16]. SK-1 cells that are first grown in pre-sporulation medium and then switched in sporulation medium (SM) will synchronously assemble SCs at 4 hours and then disassemble SCs after 7 hours in SM. We used strains NKY611 and DK428 as wild type (WT) and we used strain EW104 (ndt80A) to enrich for pachytene cells [17-21]. Strains 
Table 1. Pachytene yeast structural cell biology

\section{General cryo-ET observations}

Ladder-like densities

Stacked-ladder densities in pachytene arrest

Ordered loops of nucleosome-like particles

100-nm-wide nucleosome-free regions

\section{MTH general properties}

Presence after SM incubation

Presence in late meiosis

Presence in haploid cells in SM

Assembly timing relative to Zip1-GFP

Abundance during pachytene arrest

Sensitivity to 1,6-hexanediol

Recovery after 1,6-hexanediol washout

Subunit organization

Handedness

Oligomerization state

Packing of MTH bundles

Thickness of bundles

Presence in spo11 $\Delta$ cells

Presence in zip1 $\Delta$ cells

Presence in red $1 \Delta O$ cells

F-actin perturbation during pachytene

Rhodamine-phalloidin location

Lifeact-mCherry foci location

Treatment $\mathrm{w} / 0.1 \%$ DMSO

Treatment $\mathrm{w} / 50 \mu \mathrm{M}$ Lat-A + 0.1\% DMSO

\section{Result}

Not seen

Not seen

Not seen

At MTH bundles

$\begin{array}{ll}4-6 \text { hours } & 2 \\ \text { Absent/rare } & \text { S1A } \\ \text { Absent } & \text { S1B } \\ \text { Coincident } & \text { various } \\ \text { Increase } & 3, \text { S2 } \\ \text { Sensitive } & 4 \mathrm{D} \\ \text { Re-polymerizes } & 4 \mathrm{E} \\ \text { Triple helical } & 5 \\ \text { Right } & 5 \mathrm{D} \\ \text { Bundled } & \text { various } \\ \text { Crystalline } & 6 \\ \geq 100 \mathrm{~nm} & \text { various } \\ \text { Present } & \text { S3A } \\ \text { Present } & \text { S3B } \\ \text { Present } & \text { S3C }\end{array}$

structures meiotic triple helices (MTHs) for the following reasons. First, these MTHs densities coincide with the appearance and disappearance times of Zip1-GFP fluorescence through meiosis. Second, MTHs are absent in SM-treated haploid cells. Third, MTH abundance greatly increases in pachytene-arrested cells. We now present these experiments, which are summarized in Table 1 and Table 2. Most of the cryo-EM imaging was done by cryotomography of cryosections; 2-D projection imaging was done when the cryosection attachment was non-ideal.

To track the assembly of meiosis-specific nuclear complexes, we incubated WT cells in SM and then prepared self-pressurized-frozen samples every 2 hours for 8 hours. We then cut cryosections of these samples with nominal thicknesses of 70 or $100 \mathrm{~nm}$. To increase the contrast, we collected most of our cryoET data using a Volta phase plate [22]. Cryotomograms of cell nuclei at the start of SM treatment (0 hours) did not contain any $\sim 100$-nm-orlarger structures expected of SCs (Figure 2A). These cell nuclei contained 10-nm-diameter nucleosome-like particles and $\geq 20$-nm-wide multi-megadalton-sized complexes (megacomplexes, such as pre-ribosomes) like those seen in cryo-ET studies of yeast, insect, and HeLa nuclei [23-27]. After 2 hours in SM, a few cells had bundles of filaments (the MTHs). These MTHs each present a trefoil motif when viewed along their $\begin{array}{lll}\text { All cytoplasmic } & \text { S5, A } & \text { long axis (Figure 2B). At } 4 \text { and } 6 \text { hours in SM, the cell } \\ \text { All cytoplasmic } & \text { S5, B,C } & \text { nuclei contained larger bundles of MTHs (Figure 2, C }\end{array}$ MTH present S6, C and D). MTHs were rarely found in cells that were MTH absent

S6, D incubated for 8 hours in SM (Figure S1A).

DK428 and EW104 bear GFP-tagged Zip1 [20, 21]. Zip1-GFP is used to track the assembly of the SCs, which are markers of pachytene. With few exceptions, we use the terms wild-type (WT) and $n d t 80 \Delta$ instead of the strain names. To verify the synchronization, we incubated WT cells in SM and then classified their Zip1-GFP fluorescence signals based on published criteria [20] (Figure 1A). Diffuse Zip1-GFP fluorescence appeared in 85\% of cells $(n=75)$ after 3 hours in SM (Figure 1B). The fluorescence signals appeared punctate at 4 hours in SM, stringlike in $5-6$ hours, started to weaken in 7 hours, and were rarely visible by 8 hours (Figure 1B). Meiosis finished after 12 hours of SM incubation, at which point $97 \%$ of the cells $(n=155)$ had an ascus with 4 spores. WT cultures incubated $5-6$ hours in SM had the highest proportion of mature SC-containing cells (Figure 1C). In comparison, ndt80 $\Delta$ cells started to accumulate nuclear Zip1-GFP approximately 3 hours after SM incubation and then were arrested in pachytene as expected (Figure 1D). All these results are consistent with previous studies [20, 21].

\section{Visualization of meiotic nuclei in situ by cryo-ET}

When this study started, we expected that the most conspicuous feature of pachytene cell cryotomograms would be SC densities because sections through them should appear like 100-nm-wide zones of densely packed filaments, devoid of nucleosome-like particles. Our experiments show that previously uncharacterized large filament bundles assemble at the same time as the SCs. Herein we call the helical subunits of these uncharacterized

We did not see any MTHs in more than 1,000 cryo-ET datasets of interphase and mitotic haploid $S$. cerevisiae cells that were incubated in rich media $[23,25,28]$. Recent studies showed that when yeast cells are stressed by glucose deprivation, components of the translation machinery form large cytoplasmic filaments [29, 30]. SM contains the less-preferred acetate as the carbon source, which may induce stress-related structures that we had not seen before. To test if these nuclear filament bundles are stress-related instead of being specific to the meiosis program, we incubated the haploid strain LY2 in SM for 6 hours and then performed cryo-ET of their cryosections. Haploid cells treated this way did not contain any MTHs (Figure S1B), supporting the notion that these triple-helical structures are meiosis-specific and their being called MTHs.

\section{Pachytene-arrested cells have more MTH bundles than wild type cells}

The observation that MTH bundles and SCs appear and disappear at similar times suggests that these two structures are related. When incubated in SM, ndt80 $\Delta$ cells arrest at pachytene with SCs, but continue to express SC proteins such that nearly every $n d t 80 \Delta$ cell has a polycomplex - a large aggregate of SC proteins that resembles side-by-side stacked SCs [9, 31-33]. Polycomplexes are rare in wild-type cells of the SK-1 genetic background [17], so ndt80 $\Delta$ cells offer a means to study the correlation between SC-related structures and MTH bundles. After an 8-hour incubation in SM, ndt80 $\Delta$ cells contained both bright fluorescent spots (polycomplexes) and string-like signals 
Table 2. MTH detection by cryo-EM.

Cell line; treatment

\begin{tabular}{|c|c|c|c|}
\hline & positive & cryo-ET & projection \\
\hline spo11 $/$ spo11 & 9 & 20 & - \\
\hline 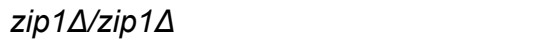 & 14 & 53 & - \\
\hline red1 $1 \Delta 0 /$ red $1 \Delta 0$ & 12 & 20 & - \\
\hline EW104 + DMSO & 15 & - & 24 \\
\hline EW104 + Lat-A & 0 & 6 & 59 \\
\hline EW104 + 5\% 1,6-hexanediol & 21 & 43 & - \\
\hline EW104 + 7\% 1,6-hexanediol & 2 & 57 & - \\
\hline EW104 + 7\% 1,6-hexanediol, washout & 27 & 38 & - \\
\hline WT in SM 8 hours & 2 & 36 & - \\
\hline LY2 (W303) in SM 6 hours & 0 & 20 & 9 \\
\hline
\end{tabular}

(SCs) in nearly every cell (Figure 3A). To verify that these cells contain polycomplexes, we prepared and then imaged plastic sections of negatively stained pachytene-arrested ndt80 $\Delta$ cells. These cells had stain distributions expected of the polycomplex [9] (Figure 3B). Cryotomograms revealed that in pachytenearrested ndt80 $\Delta$ cells, MTH bundles are larger and more numerous (Figure 3C). These structures do not appear like stacked ladders (Figure S2), but their dimensions (larger than
$500 \mathrm{~nm}$ in some cases) are comparable with that of polycomplexes [20,34].

\section{MTHs do not require SC assembly and are not composed of Zip1p or Red1p}

SCs do not assemble unless the Spo11p endonuclease is present and active [35] and cannot exist without the central-region structural protein Zip1p [36] or the lateral-element structural protein Red1p [10]. To test if MTH assembly depends on the SC, we performed additional controls with null mutants that are unable to assemble SCs, namely, spo11 $\Delta$ spo11 $\Delta$, zip1 $\Delta /$ zip $1 \Delta$, and red1 $\Delta 0 /$ red1 $\Delta 0$. Large MTH bundles were present in the all three null mutants, just like in $n d t 80 \Delta$ cells (Figure S3). We therefore conclude that MTH assembly does not depend on SC assembly and that MTHs do not contain the SC proteins Zip1p or Red1p.

\section{Ladder-like motifs and ordered chromatin are absent in meiotic yeast}

We expected to see cryo-ET densities that resemble sections through a ladder-like structure, i.e., densely packed parallel
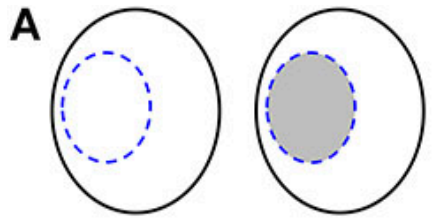

ii

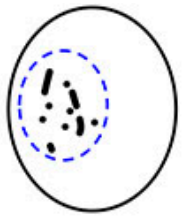

iii

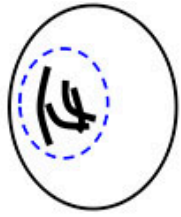

iv

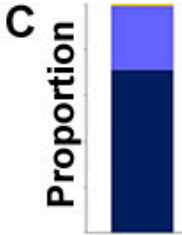

2

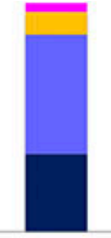

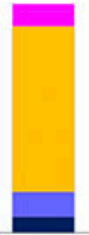

4

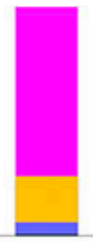

5

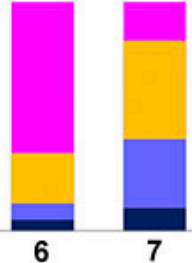

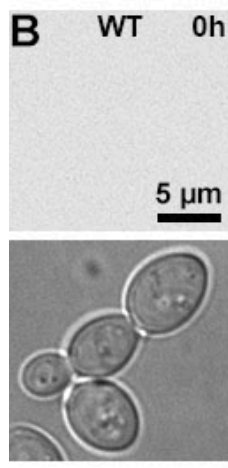

D $n d t 80 \Delta$ oh
$1 \mathrm{~h}$

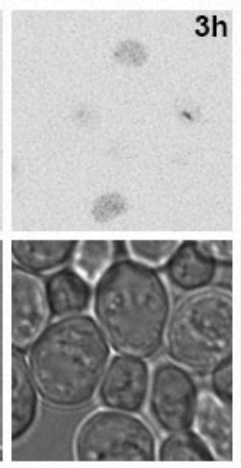

$2 \mathrm{~h}$

h

$3 \mathrm{~h}$

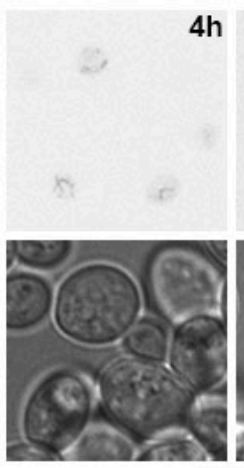

$4 \mathrm{~h}$

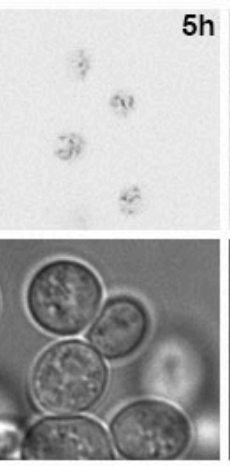

$4 \mathrm{~h}$

$5 \mathrm{~h}$
$8 \mathrm{~h}$
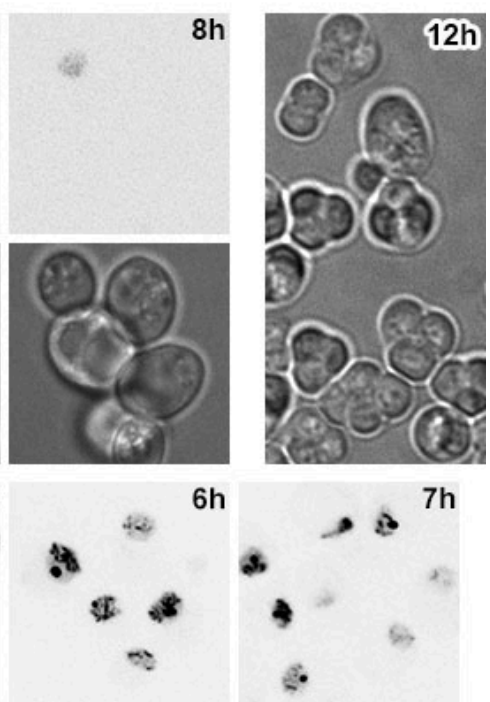

Figure 1. Meiosis monitored by their SC assembly states. (A) Cartoon of the different classes of Zip1-GFP fluorescence in meiotic prophase. i, non-fluorescent; ii, diffuse fluorescence; iii, punctate fluorescence; iv, string-like fluorescence corresponding to full-length SCs. The nucleus is blue and the Zip1-GFP signal is gray/black inside the nucleus. This schematic is based on White, et al [1]. (B) Time course of WT cells expressing Zip1-GFP in SM. Diffuse fluorescence started to appear after 2 hours and became punctate between 3 and 4 hours. Long linear SCs appeared after 5 hours in SM and became rarer after 7 hours. The right-most brightfield image shows WT cells after 12 hours in SM. Each ascus contained four spores. (C) Time course for SC formation in WT cells based on the Zip1-GFP fluorescence pattern. Approximately 100 cells were sampled at each time point. The color scheme is indicated under each cartoon in panel A. (D) Time course of $n d t 80 \Delta$ cells incubated in SM. The signal is from Zip1-GFP. 
filaments bridging a 100-nm-wide gap between two dense rails. However, we did not find ladder-like motifs in either pachytenearrested $n d t 80 \Delta$ cells or in WT cells at any of the time points we sampled. We also did not find any of the side-by-side "stacked" ladder motifs expected of polycomplexes in pachytene-arrested cells. The ladder model is based on images of traditional EM samples, which are vulnerable to fixation and staining artifacts. Furthermore, those traditional EM studies were done with projection images through tens of nanometers of cell mass, which may obfuscate the structural details of thick macromolecular complexes (Figure S4A). We tested this possibility by comparing projection images of cryosections with the increasingly thick cryotomographic slices from the same positions. In one example in which the MTHs were oriented obliquely to the cryosection surface, they appeared like filaments running parallel to the cryosection surface in the thickest tomographic slices (Figure S4, $B$ and $\mathrm{C}$ ). Projections of this bundled MTH position have a chevron motif that only vaguely resembles a ladder.

Textbooks also depict SCs as having ordered chromatin loops, which are anchored at the SC lateral elements [37, 38]. Based on this model, we would expect to find numerous rows of nucleosome-like particles (10 $\mathrm{nm}$ wide), packed side-by-side and projecting from a linear feature (the lateral element). We did not
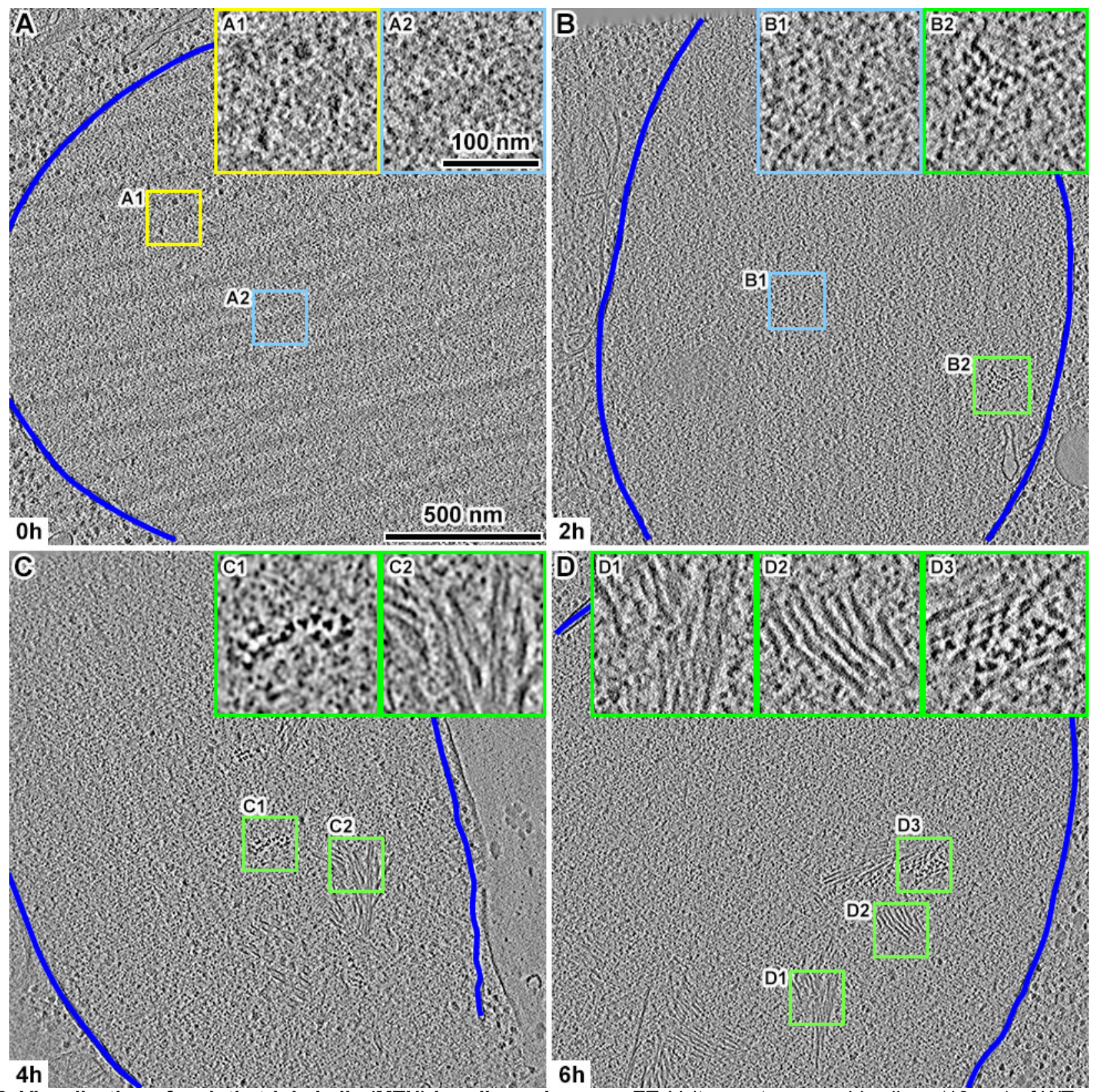

Figure 2. Visualization of meiotic triple helix (MTH) bundles using cryo-ET. Volta cryotomographic slices (10 nm) of WT cell nuclei (A) before meiosis and after (B) 2 hours, (C) 4 hours, and (D) 6 hours in SM. The boxed areas are enlarged 3-fold in the corresponding insets. Inset A1 shows 3 megacomplexes. Insets A2 and B1 show nucleosome-like particles. Insets B2, C1, and D3 show bundles of MTHs presenting a trefoil motif. Insets C2, D1, and D2 show side views of bundles of MTHs. The nuclear envelopes are delineated with the dark blue lines. 

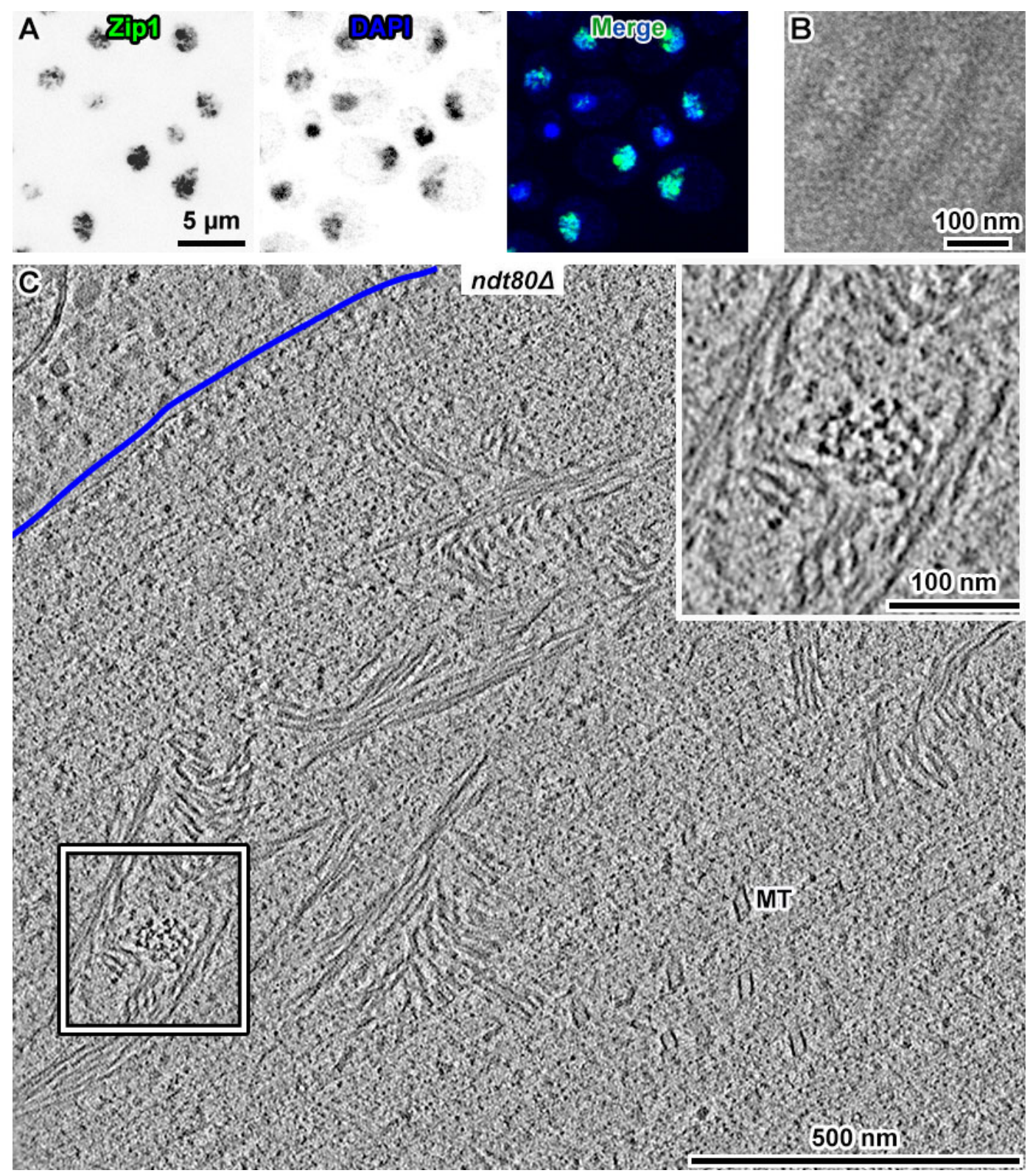

Figure 3. Pachytene-arrested cells are highly enriched in MTHs. (A) Fluorescence micrographs of pachytenearrested $n d t 80 \Delta$ cells, after 8 hours in SM. Zip1-GFP fluorescence is found at both SCs (weak fluorescence) and polycomplexes (large, bright fluorescent bodies). The chromatin is stained by DAPI. (B) Plastic section showing a portion of a polycomplex in a pachytenearrested ndt80 $\Delta$ cell. (C) Volta cryotomographic 70-nm slice of the cryosection of a ndt80 $\Delta$ cell at 8 hours in SM. The nuclear envelope (NE) is indicated by the blue line. The boxed area is enlarged 2 -fold in the inset. see periodic arrangements of nucleosome-like particles in any of the cells we imaged. This observation is consistent with the large body of data that chromatin has an irregular 3-D conformation in situ $[39,40]$.

\section{MTHs are not detected by actin-binding reagents, but depend on F-actin to assemble}

A recent study also reported novel meiotic nuclear filaments in yeast cells [41], though it is unclear if those filaments are triplehelical. Nevertheless, the similar abundance and bundling phenotypes suggest that the filaments observed by Takagi, et al are the same triple-helical structures we observed, so we will also refer to the meiotic filaments in their study as MTHs. In that study, immuno-EM showed that anti-actin antibodies [42] co-localized with the MTHs, which suggests that MTHs contain filamentous actin (F-actin). If true, then MTHs should be detectable by fluorescence-microscopy using actin probes because MTH bundles are thicker than and should have more signal than Factin filaments and patches. We stained pachytene-arrested ndt80 $\Delta$ cells with rhodamine-phalloidin and observed punctate signals in the cytoplasm (as expected), but not in the nucleus (Figure S5A). Another F-actin-visualization tool is the ABP140GFP fusion protein, which previously revealed that actin localizes to the exterior of meiotic nuclei, but not inside [1, 43]. ABP140 is probably too large to diffuse through the nuclear pore to be a nuclear-actin probe. Lifeact, the 17-amino-acid-long $\mathrm{N}$-terminal peptide of the budding yeast ABP140 gene product, is also able to bind F-actin as a GFP fusion protein [44-46]. The Lifeact-GFP fusion protein is a $29-\mathrm{kDa}$ fluorescent actin probe that is smaller than the size cutoff needed to passively diffuse through the nuclear pore complex [47]. We generated Lifeact-mCherry by integrating a mCherry tagging cassette at the 3 ' end of ABP140's 17 th codon in the EW104 strain. This strategy allows the LifeactmCherry expression levels to be controlled by the natural 
bioRxiv preprint doi: https://doi.org/10.1101/746982; this version posted May 2,2021 . The copyright holder for this preprint (which was not certified by peer review) is the author/funder, who has granted bioRxiv a license to display the preprint in perpetuity. It is made available under aCC-BY-NC-ND 4.0 International license.

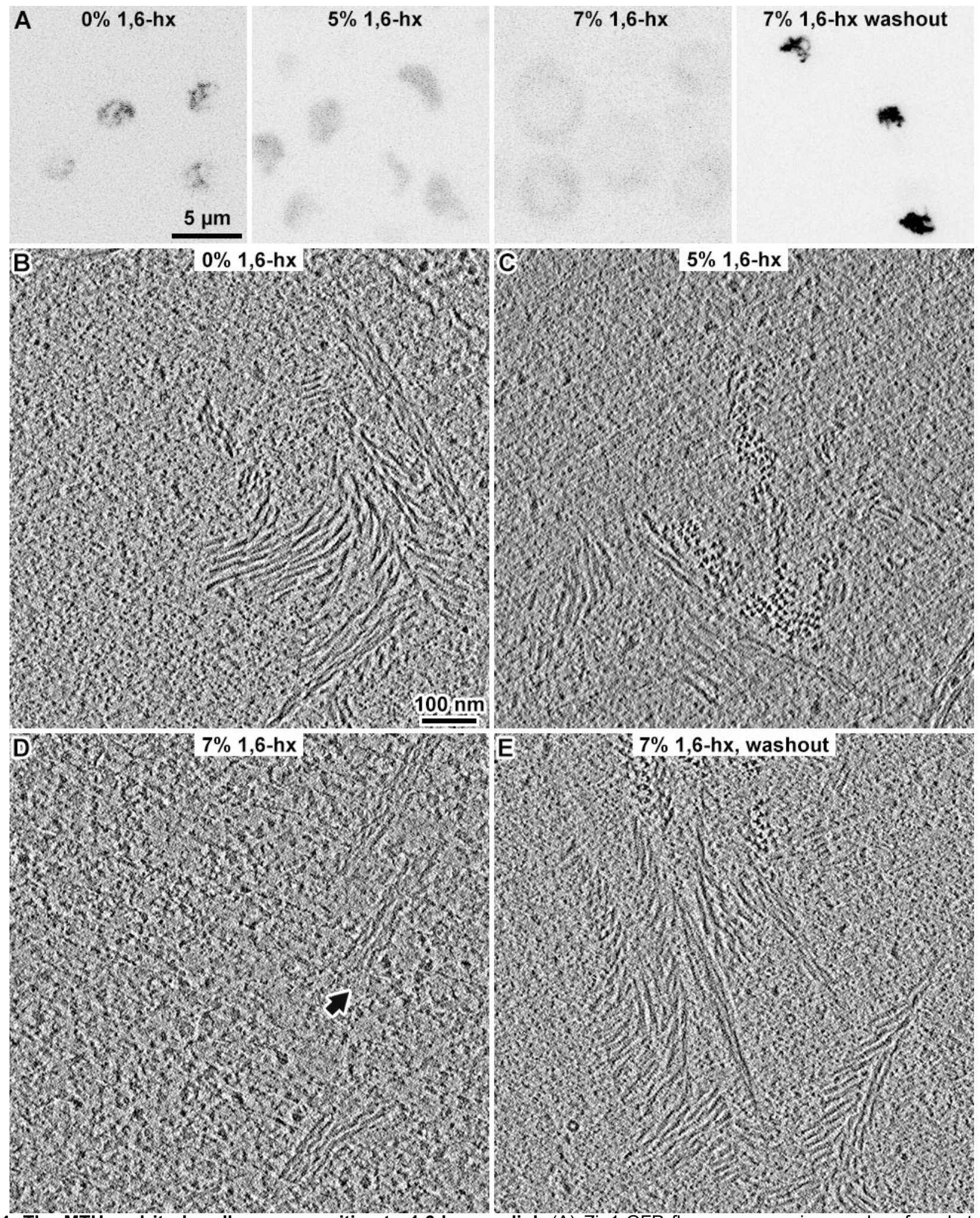

Figure 4. The MTH and its bundles are sensitive to 1,6-hexanediol. (A) Zip1-GFP fluorescence micrographs of pachytene cells treated with increasing concentrations of 1,6-hexanediol (1,6-hx), rendered with inverted contrast. The cells were harvested after 6 hours in SM and resuspended in SM with $0 \%, 5 \%$, or $7 \%$ 1,6-hexanediol. The last subpanel shows cells treated with $7 \% 1,6-$ hexanediol, then incubated in fresh SM for 5 minutes. In the 7\% 1,6-hx subpanel, the light-gray oval in the middle of the cell is the nucleus; most of the Zip1-GFP signal (darker pixels) is cytoplasmic. (B) Volta cryotomographic slice (10 nm) of a WT cell in SM, showing MTH bundles. (C) Volta cryotomographic slice $(10 \mathrm{~nm})$ of a WT cell in $5 \%$ 1,6-hexanediol. This cell contains a few MTH bundles. Approximately half the tomograms of such cells (21 of 43) contain these bundles. (D) Volta cryotomographic slice (10 nm) of a WT cell in 7\% 1,6-hexanediol. The arrow indicates a bundle of filaments of unknown structure. (E) Volta cryotomographic slice (10 nm) of a WT cell after washout of 7\% 1,6-hexanediol and then incubation in SM for 5 minutes. 
ABP140 promoter [48]. Lifeact-mCherry did not form any structures in the nuclei of pachytene-arrested ndt80 cells (Figure S5, B and C).

To further investigate the role of $\mathrm{F}$-actin in meiotic nuclei, we treated cells with Latrunculin A (Lat-A), a drug that both inhibits actin polymerization and depolymerizes F-actin [49-51]. Fluorescence microscopy showed that Lat-A-treated meiotic ndt80 $\Delta$ cells lost their cytoplasmic F-actin signals (Figure S6, A and B). Cryo-EM of cryosectioned $n d t 80 \Delta$ cells revealed that MTHs were also absent after Lat-A treatment but not after incubation with the DMSO carrier (Figure S6, C and D). Therefore, MTH assembly either requires $\mathrm{F}$-actin polymerization or is itself sensitive to Lat-A.

\section{MTHs and their bundles reversibly disassemble in 1,6- hexanediol}

An earlier study showed that 1,6-hexanediol treatment can reversibly disperse yeast SC's central region proteins [52]. To test if MTHs have similar dispersal properties, we incubated WT cells with 1,6-hexanediol for 1 minute and then imaged them by fluorescence microscopy and cryo-ET. In the presence of 5\% 1,6hexanediol, the Zip1-GFP fluorescence signals appeared uniform in the nucleus while in 7\% 1,6-hexanediol, the Zip1-GFP signal was largely cytoplasmic (Figure 4A). We then performed cryo-ET of WT cells that were treated with $0 \%$ (control), $5 \%$, or $7 \% 1,6$ - hexanediol (Figure 4, B - D). MTH bundles were present in untreated cells and in 5\% 1,6-hexandediol-treated cells (Figure 4, $B$ and $C$ ). We did not observe any MTHs in cells that were treated with $7 \%$ 1,6-hexanediol. Instead, some of the cells contained bundles of thinner filaments (Figure 4D). We attempted subtomogram 3-D classification of these 7\%-1,6-hexanediolresistant filaments but did not observe any meaningful class averages, either because these filaments are too conformationally heterogeneous or due to the limited contrast. The 7\% 1,6-hexanediol-induced disassembly is reversible because MTH bundles reform rapidly after washout (Figure 4E). MTH bundles are therefore sensitive to a slightly higher concentration of 1,6-hexanediol than SCs are and reform when 1,6-hexanediol is removed.

\section{Subtomogram 3-D analysis of the MTHs}

Cryotomographic slices of the MTHs in pachytene cells show two abundant 2-D motifs - densely packed 12-nm-wide filaments and trefoil-shaped densities that have a maximum width of 12-nm (Figure 5, A and B). When we rendered sequential tomographic slices of MTHs that were perpendicular to the cryosection surface as a movie, they appeared to rotate, consistent with their helical nature (Movie S1). To obtain a higher-resolution model of the MTHs, we performed template matching, classification, and subtomogram averaging of MTH subvolumes from three strains studied here: DK428 treated with 5\% 1,6-hexanediol after 4 hours

Figure 5. MTHs are densely packed. (A A

and B) Sequential Volta cryotomographic slices $(12 \mathrm{~nm})$ through bundles of MTHs that present the trefoil and filamentous motifs. Both are from WT cells. (C) Class averages (2-D) of template-matched MTH segments, taken from subvolumes within ndt80 $\Delta$ pachytene-arrested cells. The class averages corresponding to MTH that were used for subsequent analysis are indicated by a green triangle at the box's lower right. (D) Refined 3-D density map of MTH segments from WT, WT treated with 5\% 1,6-hexanediol (1,6-

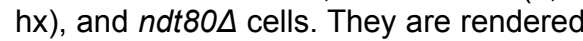
at two contour levels $(0.5 \sigma$ and $0.8 \sigma)$ and viewed both perpendicular to (upper subpanels) and along (lower subpanels) the helical axis. The handedness was confirmed by analysis of ribosomes; see Figure S7. (E) Fourier-shell correlation (FSC) plots of the MTH segments from three conditions, color-coded similarly to panel $B$. The resolutions of the averages are $~ 33 \AA$, based on the "Gold standard" $\mathrm{FSC}=0.5$ criterion.
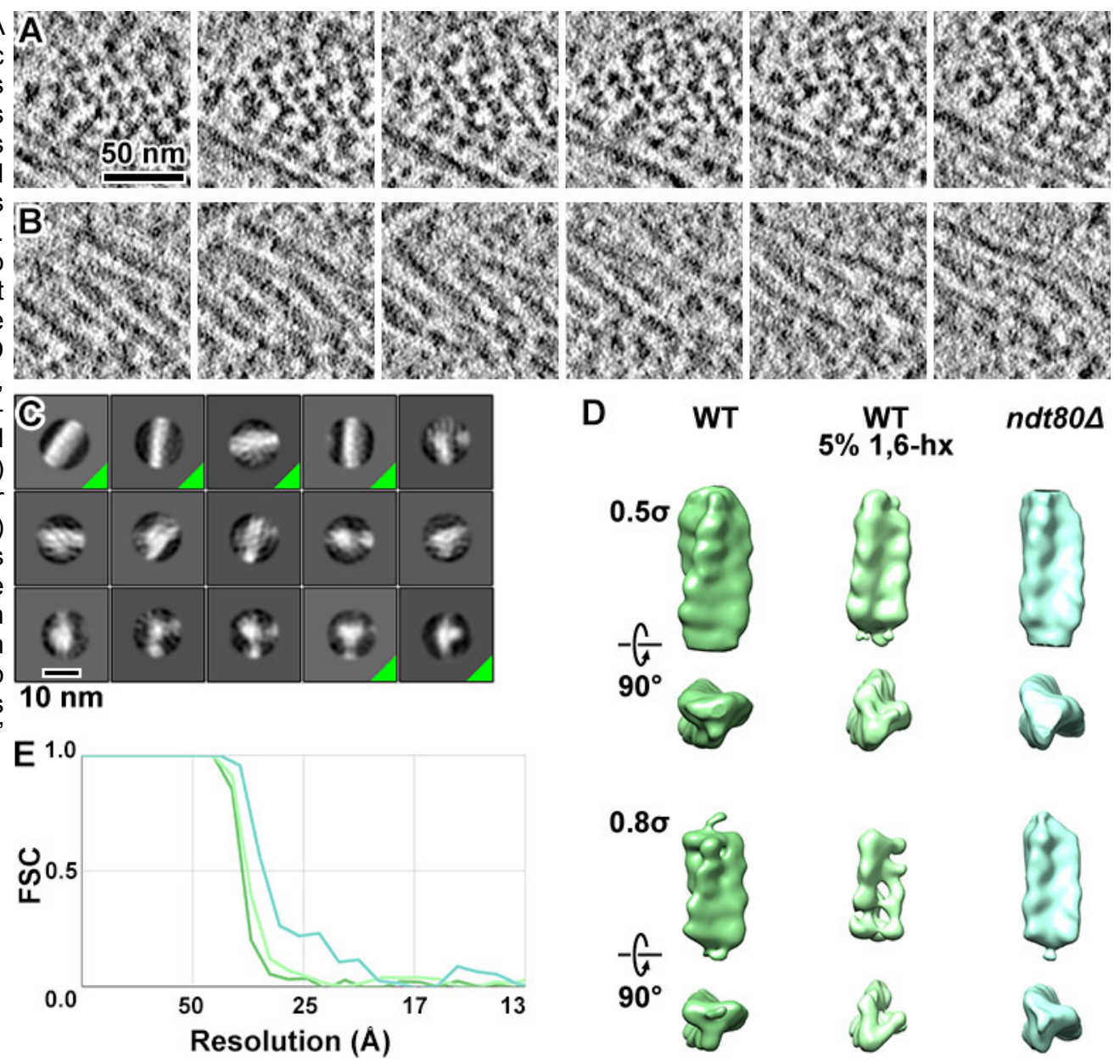

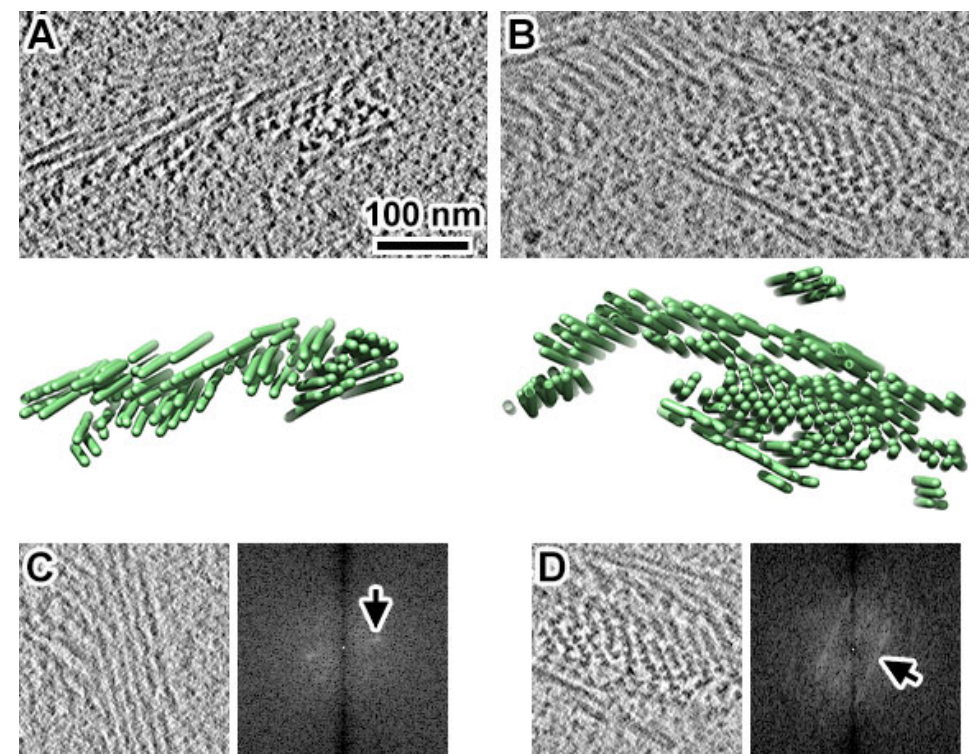

Figure 6. Yeast MTHs form crystalline bundles. (A and $B$ ) Upper: Volta cryotomographic slices $(10 \mathrm{~nm})$ of WT cells that were frozen after a 4-hour incubation in SM. Lower: 3-D models of the distribution of MTH bundles. Each MTH is rendered as a tube. (C and D) Volta cryotomographic slices (left, $10 \mathrm{~nm}$ ) and power spectra (right), taken at regions with many MTHs. Panel D shows the same MTH bundle as panel B, but from a different position along the $Z$ axis. Arrows point to elongated peaks in the power spectra, which correspond to approximately (C) $14 \mathrm{~nm}$ and (D) $22 \mathrm{~nm}$ spacings.

in SM; NKY611 after 6 hours in SM; and EW104 after 8 hours in $\mathrm{SM}$. We treated the MTH segments as independent particles, which is commonly done for single-particle analysis of helical structures [53-55]. We template matched the MTH segments with a $30-\mathrm{nm}$ long by $12-\mathrm{nm}$ diameter cylinder reference. To lower the chances of missing some MTH segments, we used a low crosscorrelation cutoff. We removed false positives by 2-D classification and then by 3-D classification (Figure 5, C and D). We then 3-D refined the particles from the best 3-D classes to 33 A resolution.

We could not distinguish between the MTHs from the three strains at the current resolution. Note that the polarity of the helix cannot be resolved in the present data, which may contribute to the averages' moderate resolution. The 3-D refined density maps confirm that the MTH is 12-nm thick (Figure 5, D and E; Movie S1), with a rise of $\sim 5 \mathrm{~nm}$. We estimate the pitch to be $\sim 130 \mathrm{~nm}$. Each strand within the MTH is $\sim 5 \mathrm{~nm}$ thick. Our attempts to obtain averages of longer MTH segments using a taller mask produced averages that resemble featureless cylinders, suggesting that the MTHs have variable curvature, which prevents their alignment and averaging to higher resolution.

All three subtomogram averages revealed right-handed MTHs. The handedness of electron tomograms is ambiguous unless a known chiral structure is imaged with the same conditions as the structure of interest [56]. Ribosomes are abundant in cellular cryotomograms and have asymmetric features that are visible in in situ subtomogram averages [24, 57]. We therefore performed template matching, classification, and subtomogram averaging of cytoplasmic ribosomes from ndt80 $\Delta$ cell cryotomograms, which had the highest contrast. One $80 \mathrm{~S}$ ribosome class average shows that the characteristic "beak" motif is oriented in the direction expected of the ribosome (Figure S7). This experiment confirms that the MTH is right-handed.

\section{MTH bundles are crystalline and helical}

To better understand how MTHs pack together, we attempted to make 3-D models of bundles of MTHs. Because the remapping of subtomogram averages can reveal higher-order motifs in chromatin structure [26, 58], we first remapped the subtomogram averages of the MTH segments back into the tomogram. This approach failed because template matching and classification are imperfect - they generate false negatives, which causes the filaments to appear discontinuous. As an alternative, we manually modeled each MTH as rod (Figure 6, A and B). The 3-D models show that MTHs form domains of largely parallel filaments that appear crystalline. To better characterize this crystallinity, we generated power spectra by Fourier transforming the tomographic slices of the largest WT filament bundles (Figure 6, $C$ and D). These power spectra revealed broad peaks corresponding to spacings between 14 and $22 \mathrm{~nm}$, consistent with hand-measured center-to-center distances between neighboring MTHs. This tight packing is consistent with the absence of macromolecular complexes, such as nucleosome-like particles, in between the MTHs. The peaks appear elongated instead of circular, meaning that MTHs pack together with helical order, namely, an MTH bundle is a helix of helices. To characterize the distribution of the MTHs, we attempted to reconstruct as much of a single cell as possible by serial Volta cryo-ET of cryosections [59]. We successfully reconstructed six sequential sections from one $n d t 80 \Delta$ cell (Figure S8). These reconstructions show that all of the MTHs in a $420-n m$-thick sample of the cell were associated in crystalline bundles. Indeed, we have not yet found an example of an isolated MTH in our other tomograms.

\section{Discussion}

\section{Meiotic yeast nuclei appear very different in the lens of cryo-ET}

In textbooks, the two most prominent features of pachytene nuclei are the ladder-like SC and the ordered chromatin loops that project from the SC's lateral elements (Figure 7A). The ladder model comes from traditional EM studies, starting with the discovery of the SC sixty-five years ago [11, 12]. This model has been supported by imaging studies of multiple organisms, including yeast [9], worms [60], beetles [61], flies [62], and plants [63]. Based on these models, one would expect our cryotomograms of pachytene yeast to contain two types of ordered motifs: 100-nm-wide ladder-like densities and densely packed rows of nucleosome chains. We did not see any densities that resemble these two ordered motifs, even when taking into account that previous EM studies were largely done by projections. What could give rise to such a discrepancy? One possibility is that the ladder-like densities seen in traditional EM are sample-preparation artifacts [14, 64]. The creation of "new" structures due to traditional-EM sample-preparation methods is a contributing factor to the appearance of the $30-\mathrm{nm}$ fiber, which has not been observed in situ by cryo-EM studies [65]. Another possibility is that the SC's subunits have a loose, ladder-like distribution, but the subunits are too thin to see by cryo-ET. In this 
A

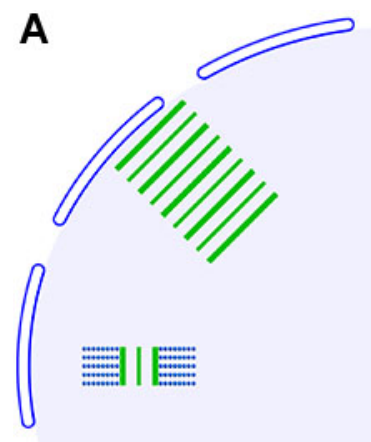

C

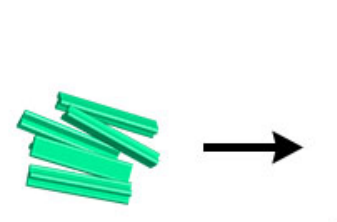

Early Meiosis I

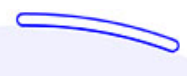

\

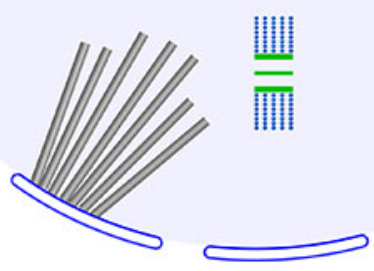

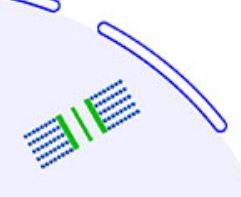

(
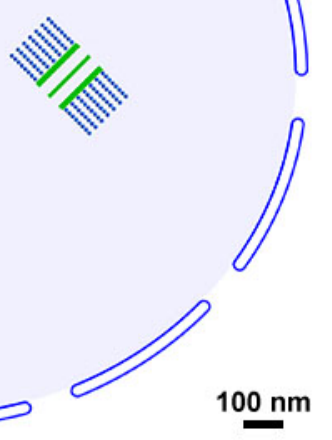

B
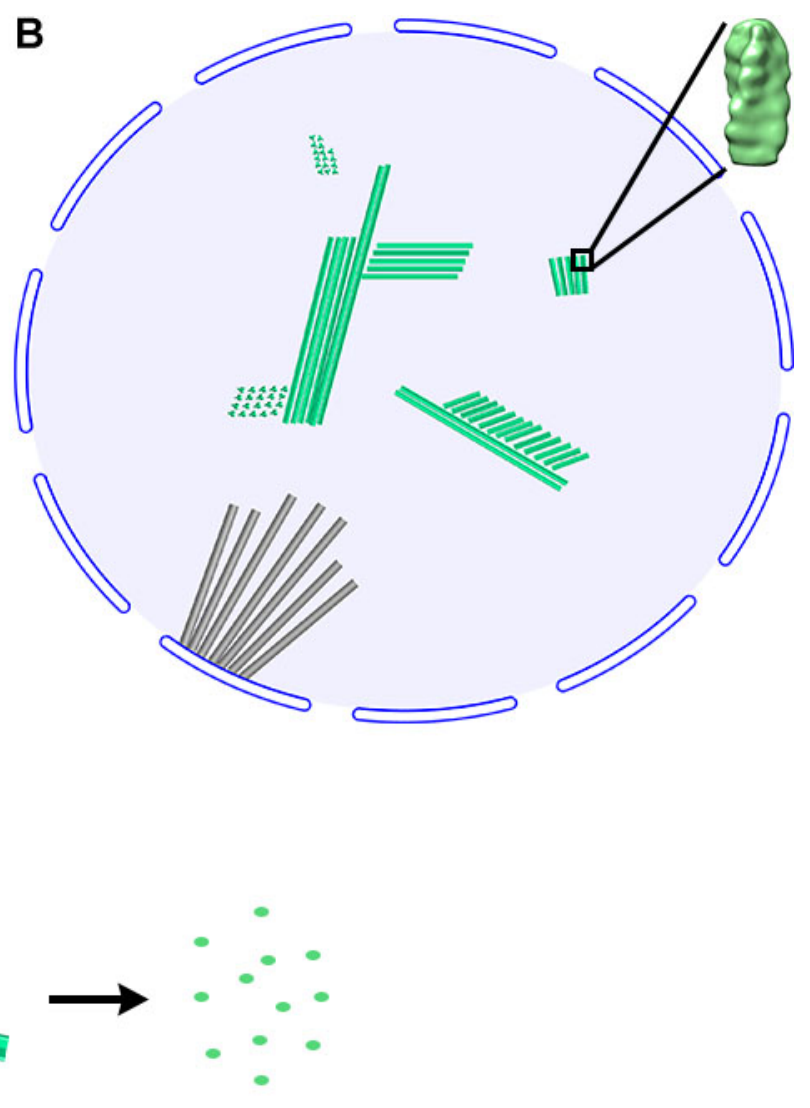

Meiosis II

Figure 7. A revised model of the meiotic yeast nucleus. (A) Traditional model of a section through a pachytene yeast nucleus. The largest structures are the nuclear-microtubule array (gray), SC sections (green and blue), and the polycomplex (parallel green lines). In the traditional model, the SC and polycomplex are densely packed structures. The nucleosomes (blue dots) project as ordered arrays from the SC. All structures are illustrated at the approximately correct scale. (B) In the revised model based on the cryo-ET analysis here, the bundles of MTHs (green polymers) are the only large, crystalline structures in pachytene-arrested cells. The MTH bundles coexist with spindle microtubules (gray tubes) and SCs, whose structure remains unknown. The chromatin, which is irregular, is represented by the uniform light-blue background. (C) MTHs form large, densely packed bundles in pachytene. These bundles are sensitive to 1,6-hexanediol (1,6-hx) and Latrunculin A (Lat-A).

case, the SC must be highly permeable because we did not observe any 100-nm-wide zones that are free of nucleosome-like (compact 10-nm diameter) particles.

\section{MTH bundles are the largest ordered structures in pachytene cells}

Instead of ladder-like structures, we observed large, crystalline bundles of MTHs, which are absent in textbook models of meiotic cells. Our cryo-ET data therefore suggest a revised model of the pachytene yeast nucleus, in which nuclear microtubules and MTH bundles are the largest structures (Figure 7B). The MTH bundles generate weak layer lines in Fourier transforms, which suggests that they pack into a helical array such as a cholesteric liquid crystal [66]. To our knowledge, no previous meiosis studies have reported MTHs in the nucleus or cytoplasm. The MTH is approximately 12-nm thick at its widest point and has a $5-\mathrm{nm}$ rise and a $130-\mathrm{nm}$ pitch. Each of the three strands is approximately 5$\mathrm{nm}$ thick. The center-to-center separation between MTHs varies from $14 \mathrm{~nm}$ to at least $22 \mathrm{~nm}$. In unperturbed cells, we did not detect isolated MTHs or thinner subassemblies, meaning that assemblies smaller than MTH bundles are rare. The rarity of smaller MTH assemblies and subassemblies suggests that the intra- and inter-MTH interactions are stable.

\section{MTH bundles have SC-like properties but lack key SC proteins}

Our study raises a major question: what is the composition of the MTH? Their identification will enable studies that address MTH's function, assembly and disassembly, relationship to actin polymerization, and the possible existence in other organisms. The MTH's SC-like properties may help their future identification and characterization. MTH and SC components share similar assembly-disassembly timings and abundance in pachytene cells (Figure 7C). They are both sensitive to 1,6-hexanediol and are localized in the nucleus, though we did see occasional MTHs in the cytoplasm. They both form large nuclear bodies that assemble in meiosis I, though only MTHs are visible by cryo-ET. These similarities led us to initially hypothesize that the MTHs are 
part of the SC. This hypothesis was falsified by our observation of MTH bundles in mutant cells that cannot assemble SCs (spo11 $)$ or that cannot produce one of the structural proteins (zip1 $\Delta$ and red1 $\triangle 0$ ). MTH bundles are therefore not part of the SC and their assembly does not depend on SCs.

Using two popular F-actin probes, rhodamine-phalloidin and Lifeact, our experiments did not detect nuclear actin. We did find that the MTHs are sensitive to the actin-depolymerizing drug LatA. In contrast, Takagi et al provided immuno-EM evidence that the similar filaments they saw (probably MTHs) contain actin [41]. While MTHs cannot be F-actin, which would appear double helical, they could instead be a non-canonical triple-helical polymer of actin that is sensitive to Lat-A and is bound by antiactin antibodies in immuno-EM experiments.

\section{Implications for recombination and chromosome segregation}

Our in situ cryo-ET observations have potential implications for crossover interference, wherein the distribution of crossovers along chromosomes is not random. Crossover interference requires rapid, long-range coordination within paired homologous chromosomes. Chromosomes and/or SCs are proposed to have mechanical properties that differ from the nucleoplasm. The beam-film model argues that chromosomes - and putatively the SCs they interact with - have built-up stress and that crossover designation locally relieves this stress [67]; the stress relief propagates locally and somehow suppresses nearby crossover designations. Another study proposed that the SC has liquidcrystal properties that allow it to function as a channel to transmit signals along chromosomes [52]. Our data suggests that yeast SCs are not crystalline because the subunits of crystalline materials contact with multiple other subunits, i.e., they are densely packed. The low-density packing of the yeast SC's subunits would not be amenable to mechanical signal propagation required for the beam-film mechanism, consistent with the finding that SCs are not required for crossover interference in yeast [68]. Unlike SCs, MTH bundles are packed with crystalline density. Molecules that have chemical properties similar to MTHs could potentially be confined within the compartment that is formed by its bundles, as proposed for SCs [52].

\section{Materials and Methods}

\section{Strains}

Strains DK428 (WT) and EW104 (ndt80A) were gifts from the Kaback lab. NKY2292, NKY2293, NKY2296 (ndt80 4 /ndt80 4 ),

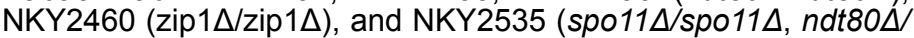
$n d t 80 \Delta$ ) were gifts from the Kleckner lab. The haploid LY2 strain was a gift from the Lacefield lab. The strains' key genotypic features and experimental roles are summarized in Table S1.

\section{Construction of Red1 deletion and Lifeact-mCherry strains}

The new strains' genotypes are also summarized in Table S1. Sequence analysis and primer design was done in Benchling [68] All of the plasmids were from Addgene (Watertown, MA) and primers (Table S2) were from IDT (Coralville, IA). Sequencing was done by Bio Basic (Bio Basic Inc., Singapore). Red1 deletion mutants (red1 $\triangle 0:: U R A 3$ and red1 $10:: K A N M X)$ of $S$. cerevisiae haploid $n d t 80 \Delta$ strains NKY2292 and NKY2293 were created by PCR-mediated gene replacement with the KANMX and URA3 markers, respectively [69]. Plasmids pFA6a-link-yoTagRFP-T-Kan (Addgene 44906) and pFA6a-link-yomCherry-CaURA3 (Addgene 44876) were purified with QIAprep spin miniprep kit (QIAGEN, Hilden, Germany, digested with restriction enzyme Sacl-HF (NEB, Ipswich, MA), and served as templates for the KANMX and URA3 deletion cassettes, respectively. The extension PCR amplicons have $40 \mathrm{bp}$ of homologous sequences upstream and downstream of RED1 and were amplified with Q5 polymerase (NEB). Haploid cells were transformed by the lithium acetate/ single-stranded carrier DNA/PEG4000 method [70]. MATa cells (NKY2292 background, red1 $10:: K A N M X$ ) cells were recovered in $1 \mathrm{~mL}$ YPD (1\% yeast extract, 2\% Bacto peptone, 2\% D-glucose) at $30^{\circ} \mathrm{C}$ in a ThermoMixer $\mathrm{C}$ (Eppendorf, Hamburg, Germany) for 3 hours (200 RPM) before plating. MATa cells (NKY2293 background, red1 $\triangle 0:: U R A 3$ ) were selected in synthetic defined - uracil media. DNA was extracted from transformants via the LiAc-SDS gDNA method [71]. Single MATa and MATa red1 $\triangle 0$ colonies grown on YPD plates were mixed and spread onto double-selection plates (+G418, synthetic defined medium, -uracil, with monosodium glutamate as the nitrogen source). For Lifeact-mCherry strain construction, pFA6a-link-yomCherry-Kan (Addgene 44903) were linearized with Sacl-HF(NEB, Ipswich, MA). PCR tagging cassettes were amplified from this plasmid to contain up to around 50 base pairs of homology sequences with upstream and downstream of the 17th codon of ABP140. These PCR cassettes insert in-frame at the 3' end of the 17th codon of ABP140. The PCR cassette was then transformed into EW104 to create LGY0069 using the lithium acetate method [72]. All strains were also validated by PCR and Sanger sequencing.

\section{Cell culture and synchronization}

Most experiments were done at room temperature $\left(23^{\circ} \mathrm{C}\right)$ unless noted otherwise. Cells were sporulated using a previous protocol $[17,20]$, modified as follows. A single colony from a YPD plate was inoculated into $3 \mathrm{~mL}$ YPD medium and grown overnight at $30^{\circ} \mathrm{C}$ with shaking at $220 \mathrm{RPM}$ in a $15 \mathrm{~mL}$ culture tube. Cells were pelleted at $3,000 \times \mathrm{g}$ for 5 minutes, washed once with $\mathrm{ddH} 2 \mathrm{O}$ (deionized and distilled water, $\geq 18 \mathrm{M} \Omega \cdot \mathrm{cm}$ ) and then resuspended in $20 \mathrm{~mL}$ YPA $(0.5 \%$ yeast extract, $1 \%$ Bacto peptone, $1 \%$ potassium acetate; pre-sporulation medium) in a $250 \mathrm{~mL}$ flask, which was used for all subsequent incubations. After a 3-hour pre-sporulation incubation at $30^{\circ} \mathrm{C}$, the cells were pelleted, washed three times with $\mathrm{ddH} 2 \mathrm{O}$, and then resuspended in $20 \mathrm{~mL}$ sporulation medium (SM $-2 \%$ potassium acetate) with $0.5 \mathrm{~mL}$ amino-acid supplement $(0.04 \mathrm{~g} / \mathrm{L}$ L-proline, $0.02 \mathrm{~g} / \mathrm{L} \mathrm{L}$ lysine, $0.08 \mathrm{~g} / \mathrm{L}$ L-tyrosine, $0.2 \mathrm{~g} / \mathrm{L}$ L-histidine, $0.2 \mathrm{~g} / \mathrm{L}$ L-leucine, $0.2 \mathrm{~g} / \mathrm{L}$ L-methionine, $0.2 \mathrm{~g} / \mathrm{L}$ L-tryptophan, $0.2 \mathrm{~g} / \mathrm{L}$ L-arginine, 0.4 g/L Adenine, $0.4 \mathrm{~g} / \mathrm{L}$ Uracil, $1 \mathrm{~g} / \mathrm{L}$ L-phenylalanine; Sigma LAA21; Sigma, St. Louis, MO). Sporulation was done at $30^{\circ} \mathrm{C}$ with shaking.

\section{Treatment with 1,6-hexanediol}

Six molar 1,6-hexanediol (Sigma 88571) was diluted with ddH2O to a final concentration of $10 \%$ or $14 \%(\mathrm{w} / \mathrm{v})$. DK428 cells $(1 \mathrm{~mL})$ were incubated for 6 hours in SM and then transferred to a 1.5 $\mathrm{mL}$ microfuge tube and centrifuged at $3,000 \times \mathrm{g}$ for 5 minutes. The cell pellet was resuspended with $0.5 \mathrm{~mL}$ ddH2O. For $5 \%$ or $7 \%(0.42 \mathrm{M}$ or $0.59 \mathrm{M}$, respectively) hexanediol treatment, $0.5 \mathrm{~mL}$ of $10 \%$ or $14 \%$ hexanediol solution was added to $0.5 \mathrm{~mL}$ of cell suspension and then mixed by pipetting for 1 minute. Fluorescence microscopy was performed on $4 \mu \mathrm{l}$ of 1,6- 
hexanediol-treated cell mixture that was spread onto a microscope slide.

\section{Treatment with Latrunculin A}

EW104 (ndt80A) cells were sporulated for 6 hours and then treated with $0.5 \%$ DMSO (Sigma D2650; the carrier) or $50 \mu \mathrm{M}$ Latrunculin A (Abcam 144290; Abcam, Cambridge, UK) for 2 hours, at $30^{\circ} \mathrm{C}$ with shaking at 220 RPM. For cryo-ET, the cells were pelleted by centrifugation at $3,000 \times \mathrm{g}$ for 5 minutes at $23^{\circ} \mathrm{C}$, then subjected to self-pressurized freezing and vitreous sectioning. For LM, the cells were fixed with $3.7 \%$ formaldehyde (Sigma F8775) in SM for 1 hour at $30^{\circ} \mathrm{C}$, then washed with $\mathrm{ddH} 2 \mathrm{O}$ three times. The fixed cells were resuspended in $500 \mu \mathrm{l}$ PBS $+0.1 \%$ Triton-X100 with $1 \mu$ l Rhodamine Phalloidin reagent (Abcam 235138) and incubated at $23^{\circ} \mathrm{C}$ with rotation for 20 minutes. The cells were washed with $\mathrm{ddH} 2 \mathrm{O}$ and imaged by fluorescence microscopy.

\section{Fluorescence microscopy of time course experiments}

Sporulating cells were fixed with $4 \%$ paraformaldehyde (Electron Microscopy Sciences, 15714) in SM for 60 minutes at $30^{\circ} \mathrm{C}$ and then pelleted by centrifugation at $3,000 \times \mathrm{g}$ for 5 minutes. Three $\mu \mathrm{l}$ of cells were added to a microscope slide. For the fixed cells, the DNA was stained with Vectashield-DAPI (Vector Laboratories, Inc. \#H-1200-10, Burlingame, CA). Images were recorded using a PerkinElmer Ultraview Vox (Waltham, MA) spinning disc confocal microscope with a $100 \times$ oil-immersion objective lens.

\section{Fluorescence microscopy of Lifeact-mCherry expressing cells}

Pachytene-arrested LGY0069 cells were concentrated and $1.5 \mu \mathrm{L}$ of cells were mounted onto an SM agarose pad to enable live-cell imaging. A coverslip was placed above the sample and sealed with Vaseline. Images were recorded at $30^{\circ} \mathrm{C}$ using an Olympus IX 83 inverted microscope with an Olympus UPLSAPO60xO objective lens (Olympus, Tokyo, Japan). Temperature control was monitored using Oko lab stage insert chamber (Olympus) to ensure the set-up was kept at $30^{\circ} \mathrm{C}$. Laser diodes (488 $\mathrm{nm}$ and $561 \mathrm{~nm}$ ) were used to drive fluorescence signals from Zip1-GFP and Lifeact-mCherry, respectively.

\section{Plastic sectioning}

EW104 (ndt80A) cells were harvested after an 8-hour SM incubation and then fixed with 4\% paraformaldehyde in SM for 1 hour at $30^{\circ} \mathrm{C}$. The fixed cells were washed three times with water and then partially lysed with a yeast nuclei isolation kit (Abcam 206997) using the following modified protocol, using buffers from the kit unless otherwise stated. The cell pellet was resuspended in $1 \mathrm{~mL}$ Buffer $\mathrm{A}$ (with $10 \mathrm{mM}$ dithiothreitol added), then incubated for 10 minutes in a $30^{\circ} \mathrm{C}$ water bath. Cells were pelleted at 1,500 $\times \mathrm{g}$ for 5 minutes at $23^{\circ} \mathrm{C}$ and resuspended in $1 \mathrm{~mL}$ Buffer $\mathrm{B}$. After addition of $10 \mu \mathrm{l}$ lysis enzyme cocktail, the cells were incubated at $30^{\circ} \mathrm{C}$ for 15 minutes with shaking at 220 RPM and then pelleted at $1,500 \times \mathrm{g}$ at $4^{\circ} \mathrm{C}$. The cell pellet was resuspended in Buffer $\mathrm{C}$, incubated at $23^{\circ} \mathrm{C}$ for 10 minutes, and then washed in $\mathrm{ddH} 2 \mathrm{O}$. Plastic sections were prepared from this cell pellet using a published protocol [32] that was modified as follows. The partially lysed cells were dehydrated at $23^{\circ} \mathrm{C}$ with sequential treatments: $70 \%$ ethanol (20 minutes) $\rightarrow 90 \%$ ethanol (20 minutes) $\rightarrow$ 95\% ethanol (20 minutes) $\rightarrow 100 \%$ ethanol (20 minutes, twice) $\rightarrow 50 \%$ ethanol: $50 \%$ LR White (hard grade, London Resin Company) (1 hour) $\rightarrow 100 \%$ LR White (overnight).
The cells were transferred into a gelatin capsule filled with LR White resin and then polymerized at $50^{\circ} \mathrm{C}$ for 24 hours. Plastic sections (80 nm nominal) were cut in a Leica Ultracut UCT/FCS (Leica Microsystems, Vienna, Austria) with a glass knife, floated onto a water trough, collected with a 200 mesh continuouscarbon EM grid, and stained with UranyLess (EMS 22409; Electron Microscopy Sciences, Hatfield, PA) at $23^{\circ} \mathrm{C}$ for 1 hour. Projection images of plastic sections were recorded with a Tecnai T12 transmission electron cryomicroscope (TFS) using a $4 \mathrm{k} \times 4 \mathrm{k}$ Gatan UltraScan CCD camera (Gatan, Inc., Pleasanton, CA).

\section{Self-pressurized freezing and vitreous sectioning}

Cells were self-pressurized frozen using a method modified from [73]. Sporulating cells were pelleted by centrifugation at 3,000 $\times \mathrm{g}$ for 5 minutes at $23^{\circ} \mathrm{C}$. The cell pellet was mixed with $60 \%$ dextran (Mr = $40 \mathrm{kDa}$, Sigma 31389) in SM. The cell/dextran mixture was quick-spun for 30 seconds to pop the bubbles and then loaded into a copper tube $(0.3 \mathrm{~mm}$ inner diameter) with a syringe-type filler device (part 733-1, Engineering Office $M$. Wohlwend $\mathrm{GmbH}$ ). Both ends of the copper tube were tightly clamped with flat-nosed pliers and then dropped into liquid ethane. Before loading into the microtome, the tubes' clamped ends were cut off with a tube-cut device (Part. 732, Engineering Office $\mathrm{M}$. Wohlwend $\mathrm{GmbH}$ ) operated in liquid nitrogen.

EM grids were pre-coated with $4 \mu \mathrm{l}$ of $0.1 \mathrm{mg} / \mathrm{ml}$ BSA with $10-\mathrm{nm}$ colloidal gold beads (Sigma G1527) in ddH2O and air dried for either 3 hours or overnight before use. Vitreous sections of 70 or $100 \mathrm{~nm}$ nominal thickness were cut with a diamond knife (16DIA.DCO3530; Diatome, Nidau, Switzerland) in a Leica UC7/ FC7 cryo ultramicrotome operated at $-150^{\circ} \mathrm{C}$ and augmented by dual micromanipulators $[59,74,75]$. The ribbon was attached to the gold pre-coated EM grid by charging with a Crion device (Leica Microsystems) in charge mode for 1 minute. The grid was stored in liquid nitrogen until imaging.

\section{Electron cryotomography imaging and reconstruction}

Tilt series were collected on Titan Krios (TFS) transmission electron cryomicroscopes equipped with a Volta phase plate, using either a Falcon II direct-detection camera (TFS) or a BioQuantum K3-GIF camera (Gatan, Inc.). Falcon II images were recorded in integration mode with Tomo4 (TFS). K3 dosefractionated super-resolution movies were recorded under the control of SerialEM [76], with summed frames saved every 100 milliseconds. Additional imaging parameters are listed in Table S3. Cryotomogram reconstruction was performed semiautomatically using the batch processing function of the IMOD software package [77-79]. The tilt series were aligned using either the gold beads as fiducials or by patch tracking if the field of view did not have enough gold beads. Contrast transfer function compensation (phase flipping, using IMOD ctfphaseflip) was done for the defocus phase-contrast data but not for Volta phase-contrast data. All cryotomograms analyzed in this paper are detailed in Table S4.

\section{Cryo-EM projection imaging of cryosections}

For projections, 9 images were recorded with Volta phase contrast on a Falcon II camera, of haploid-cell cryosections. 83 projections were recorded with defocus phase contrast on a K3GIF camera. See the bottom of Table S4 for additional details.

Template matching and initial model 
References were created with the Bsoft program beditimg [80] while masks were created with beditimg and the RELION (REgularised LIkelihood OptimisatioN) program relion_mask_create [81]. Uniformly spaced search points were seeded with the PEET program gridlnit (Particle Estimation for Electron Tomography) [82, 83]. Template matching was done using PEET. We used different template-matching strategies for MTHs and ribosomes as detailed in Table S5. MTH filaments are long and curvy, so they had to be treated as short helical segments. The grid points fit in a rectangular box that enclosed the MTH bundles. The search was done with $10^{\circ}$ angular increments and using a Gaussian low-pass filter that attenuates spatial frequencies beyond $10-\mathrm{nm}$ resolution. To minimize the influence of nearby particles, the subtomograms were masked by a cylinder (MTH) or sphere (ribosome) that was extended 1 to 2 $\mathrm{nm}$ beyond the reference's outer-most pixels. Only one round of template matching was done, i.e., the reference was not refined. To lower the number of false negatives, we used a very low cross-correlation cutoff of $\sim 0.1$ to 0.3 . This criterion resulted in more than 10-fold excess of false positives, as assessed by comparing the number of hits that remained after the classification process described below. A second round of template matching was done using the knowledge gained from subtomogram classification analysis as detailed in the next section.

\section{Subtomogram classification}

Subtomogram classification and averaging were performed using RELION's subtomogram-analysis routines [84-86]. Twodimensional classification of the projected subtomograms revealed class averages that clearly distinguished between the MTH densities and globular structures [84]. For 3-D classification, a 24-nm tall, 7-nm diameter cylindrical rod was used as a reference. To suppress the influence of neighboring particles, the densities were masked with a 16-nm tall, 19-nm-diameter softedged cylinder. No symmetry was enforced. Some of the resultant 3-D class averages were clearly MTHs, based on their dimensions and helical appearance. Other 3-D class averages had poorly defined shapes and were excluded as false positives. To improve the detection of false positives, the dimensions (length and radius) of the mask were varied. A taller cylindrical mask $(24 \mathrm{~nm})$ enabled the detection of rod-shaped densities that are shorter than the MTH. This new mask also probably caused the removal of the template-matching hits of MTHs close to the cryosection surface, where cryosectioning artifacts and contaminants generate spurious densities. Two rounds of 3-D classification using this taller mask pruned the dataset to a few thousands subtomograms. These subtomograms were then subjected to "gold-standard" 3-D autorefinement, but using a shorter, 16-nm-tall mask. Use of the shorter mask resulted in class averages that have higher-resolution features, such as 5$\mathrm{nm}$ periodic density bumps along the helical axis. These features were absent when taller masks were used probably because the MTHs have variable curvatures, which make the MTH segments more heterogeneous. The resultant higher signal-to-noise-ratio class average allowed us to more accurately measure the diameters and design a skinnier cylindrical template. Furthermore, this shorter class average (and correspondingly shorter cylindrical mask) was used for a second round of template matching, but with a denser search grid to maximize the number of MTH-containing subtomograms detected. The second set of template-matching hits was filtered at a cross-correlation coefficient cutoff of 0.2 . This cutoff was determined subjectively by incremental increases, followed by inspection of the hit positions in the cryotomograms. The cutoff was chosen such that a nearly equal number of obvious nucleoplasmic false positives, such as nucleosome-like particles, were also included. These hits were 2-D and 3-D classified again.
Three-dimensional refinement was done using 841, 1,513, and 4,456 MTH segments from NKY611, DK428, and EW104 cells, respectively. Preliminary $3-D$ refinement on EW104 MTH segments produced a Fourier shell correlation curve that did not drop to zero in the highest-resolution range. This artifact was caused by new "duplicate" particles that were generated by the 3D classification translational search [26]. These duplicates were removed by re-running template matching with PEET, using only the coordinates of the $3-D$ classified particles. The remaining 4,161 MTH segments were re-refined in RELION. FSCs were plotted with Google Sheets (Alphabet, Inc., Mountain View, CA). Subtomogram average visualization was done with UCSF Chimera [87].

\section{Fourier analysis}

To maximize the signal-to-noise ratio for Fourier analysis of MTHs, positions with the largest bundles of MTHs were selected. Tomographic slices $(10 \mathrm{~nm})$ were exported as TIFF files using the IMOD slicer tool and then read into FIJI v2.0.0 [88]. A 512-pixelwide rectangular selection was made around the bundled MTHs and then Fourier transformed using the FFT tool. The distance $\mathrm{d}^{*}$, in inverse pixels, between a peak's center of mass and the origin was measured using the straight-line tool. This distance was converted to real space units with the equation

$\mathrm{d}=512 \times$ pixel $/ \mathrm{d}^{*}$

In this equation, "pixel" is the real-space pixel size $(0.58 \mathrm{~nm})$.

\section{Ribosome density simulation}

The ribosome density map was simulated from the $80 \mathrm{~S}$ ribosome crystal structure [89] using the Bsoft program bgex [80]. An image of the mirrored map was created directly in UCSF Chimera (Pettersen, 2004\} with the command vop zflip.

\section{Data sharing}

The subtomogram average of the wild-type MTH has been deposited as EMDB entry EMD-31081. All the tilt series raw data for cryotomograms analyzed in this paper (Table S5) have been deposited in EMPIAR [90] as entry EMPIAR-10670. Data that was collected for this study but not fully analyzed, i.e., "surplus" tilt series and tomograms, will be deposited in EMPIAR-10227 [28].

\section{Author Contributions and Notes}

OXM and LG - experiments, project design, writing; WGC, JKEL, CAS, AH - experiments, writing; $\mathrm{PZ}$ and US - writing; SC, JS, and LG - training.

The authors declare no conflict of interest. This article contains supplemental information online.

\section{Acknowledgments}

We thank the CBIS microscopy staff for support and training. We thank Soni Lacefield, David Kaback, Tadasu Nozaki, and Nancy Kleckner for sharing strains and for their advice. We thank Mikhail Eltsov for recognizing that the MTH bundles resemble a cholesteric phase and Akira Shinohara for sharing results prior to publication. We acknowledge Diamond Light Source for access and support of the cryo-EM facilities at the UK's national Electron 
Bio-imaging Centre (eBIC) [under proposal BI23297], funded by the Wellcome Trust, MRC and BBRSC. US was funded by the Biomedical Research Council of A*STAR (Agency for Science, Technology and Research), Singapore. OXM, SC, WGC, JKEL, and LG were supported by a Singapore Ministry of Education Tier 1 grants R-154-000-A49-114 and R-154-000-B42-114 and Tier 2 grant MOE2019-T2-2-045.

\section{References}

1. Koszul, R., et al., Meiotic chromosomes move by linkage to dynamic actin cables with transduction of force through the nuclear envelope. Cell, 2008. 133(7): p. 1188-201.

2. Keeney, S., C.N. Giroux, and N. Kleckner, Meiosis-specific DNA double-strand breaks are catalyzed by Spo11, a member of a widely conserved protein family. Cell, 1997. 88(3): p. 375-84.

3. Roeder, G.S., Sex and the single cell: meiosis in yeast. Proc Natl Acad Sci U S A, 1995. 92(23): p. 10450-6.

4. Page, S.L. and R.S. Hawley, The genetics and molecular biology of the synaptonemal complex. Annu Rev Cell Dev Biol, 2004. 20: p. 525-58.

5. Zickler, D. and N. Kleckner, Recombination, Pairing, and Synapsis of Homologs during Meiosis. Cold Spring Harb Perspect Biol, 2015. $7(6)$.

6. Zickler, D. and N. Kleckner, Meiotic chromosomes: integrating structure and function. Annu Rev Genet, 1999. 33: p. 603-754.

7. Schmekel, K. and B. Daneholt, The central region of the synaptonemal complex revealed in three dimensions. Trends Cell Biol, 1995. 5(6): p. 239-42.

8. Voelkel-Meiman, K., et al., SUMO localizes to the central element of synaptonemal complex and is required for the full synapsis of meiotic chromosomes in budding yeast. PLoS Genet, 2013. 9(10): p. e1003837.

9. Zickler, D. and L.W. Olson, The synaptonemal complex and the spindle plaque during meiosis in yeast. Chromosoma, 1975. 50(1): $p$. 1-23.

10. Smith, A.V. and G.S. Roeder, The yeast Red1 protein localizes to the cores of meiotic chromosomes. J Cell Biol, 1997. 136(5): p. 957-67.

11. Moses, M.J., Chromosomal structures in crayfish spermatocytes. J Biophys Biochem Cytol, 1956. 2(2): p. 215-8.

12. Fawcett, D.W., The fine structure of chromosomes in the meiotic prophase of vertebrate spermatocytes. J Biophys Biochem Cytol, 1956. 2(4): p. 403-6.

13. Carpenter, A.T., Electron microscopy of meiosis in Drosophila melanogaster females. I. Structure, arrangement, and temporal change of the synaptonemal complex in wild-type. Chromosoma, 1975. 51(2): p. 157-82.

14. Byers, B. and L. Goetsch, Electron microscopic observations on the meiotic karyotype of diploid and tetraploid Saccharomyces cerevisiae. Proc Natl Acad Sci U S A, 1975. 72(12): p. 5056-60.

15. Ng, C.T. and L. Gan, Investigating eukaryotic cells with cryo-ET. Mol Biol Cell, 2020. 31(2): p. 87-100.

16. Kane, S.M. and R. Roth, Carbohydrate metabolism during ascospore development in yeast. J Bacteriol, 1974. 118(1): p. 8-14.

17. Padmore, R., L. Cao, and N. Kleckner, Temporal comparison of recombination and synaptonemal complex formation during meiosis in S. cerevisiae. Cell, 1991. 66(6): p. 1239-56.

18. $\mathrm{Xu}$, L., et al., NDT80, a meiosis-specific gene required for exit from pachytene in Saccharomyces cerevisiae. Mol Cell Biol, 1995. 15(12): p. $6572-81$.

19. Chu, S. and I. Herskowitz, Gametogenesis in yeast is regulated by a transcriptional cascade dependent on Ndt80. Mol Cell, 1998. 1(5): p. 685-96.
20. White, E.J., et al., In vivo analysis of synaptonemal complex formation during yeast meiosis. Genetics, 2004. 167(1): p. 51-63.

21. Scherthan, $H_{\text {., }}$ et al., Chromosome mobility during meiotic prophase in Saccharomyces cerevisiae. Proc Natl Acad Sci U S A, 2007. 104(43): p. 16934-9.

22. Fukuda, Y., et al., Electron cryotomography of vitrified cells with a Volta phase plate. J Struct Biol, 2015. 190(2): p. 143-54.

23. Chen, C., et al., Budding yeast chromatin is dispersed in a crowded nucleoplasm in vivo. Mol Biol Cell, 2016. 27(21): p. 3357-3368.

24. Cai, S., et al., Cryo-ET reveals the macromolecular reorganization of S. pombe mitotic chromosomes in vivo. Proc Natl Acad Sci U S A, 2018. 115(43): p. 10977-10982.

25. $\mathrm{Ng}, \mathrm{C} . \mathrm{T}$., et al., Electron cryotomography analysis of Dam1C/DASH at the kinetochore-spindle interface in situ. J Cell Biol, 2019. 218(2): $p$. 455-473.

26. Cai, S., et al., The in situ structures of mono-, di-, and trinucleosomes in human heterochromatin. Mol Biol Cell, 2018. 29(20): p. 2450-2457.

27. Eltsov, M., et al., Nucleosome conformational variability in solution and in interphase nuclei evidenced by cryo-electron microscopy of vitreous sections. Nucleic Acids Res, 2018. 46(17): p. 9189-9200.

28. Gan, L., et al., A collection of yeast cellular electron cryotomography data. Gigascience, 2019. 8(6).

29. Marini, G., et al., Reorganization of budding yeast cytoplasm upon energy depletion. Mol Biol Cell, 2020. 31(12): p. 1232-1245.

30. Nuske, E., et al., Filament formation by the translation factor elF2B regulates protein synthesis in starved cells. Biol Open, 2020. 9(7).

31. Sym, M. and G.S. Roeder, Zip1-induced changes in synaptonemal complex structure and polycomplex assembly. J Cell Biol, 1995. 128(4): p. 455-66.

32. Schmekel, K., Methods for immunoelectron microscopic and fine structural analysis of synaptonemal complexes and nodules in yeast. Chromosoma, 2000. 109(1-2): p. 110-6.

33. Bhuiyan, H., G. Dahlfors, and K. Schmekel, Lateral elements inside synaptonemal complex-like polycomplexes in ndt80 mutants of yeast bind DNA. Genetics, 2003. 163(2): p. 539-44.

34. Dong, H. and G.S. Roeder, Organization of the yeast Zip1 protein within the central region of the synaptonemal complex. J Cell Biol, 2000. 148(3): p. 417-26.

35. Giroux, C.N., M.E. Dresser, and H.F. Tiano, Genetic control of chromosome synapsis in yeast meiosis. Genome, 1989. 31(1): p. 88-94.

36. Sym, M., J.A. Engebrecht, and G.S. Roeder, ZIP1 is a synaptonemal complex protein required for meiotic chromosome synapsis. Cell, 1993. 72(3): p. 365-78.

37. Alberts, B., Molecular biology of the cell. Sixth edition. ed. 2015, New York, NY: Garland Science, Taylor and Francis Group. 1 volume (various pagings).

38. Morgan, D.O., The cell cycle : principles of control. Primers in biology. 2007, London: Published by New Science Press in association with Oxford University Press; Distributed inside North America by Sinauer Associates, Publishers. xxvii, 297 p.

39. Hansen, J.C., et al., The 10-nm chromatin fiber and its relationship to interphase chromosome organization. Biochem Soc Trans, 2018. 46(1): p. 67-76.

40. Maeshima, K., et al., Fluid-like chromatin: Toward understanding the real chromatin organization present in the cell. Curr Opin Cell Biol, 2020. 64: p. 77-89.

41. Takagi, T., M. Osumi, and A. Shinohara, Nuclear actin cable with multiple branches during yeast meiosis. bioRxiv, 2019.

42. Lessard, J.L., Two monoclonal antibodies to actin: one muscle selective and one generally reactive. Cell Motil Cytoskeleton, 1988. 10(3): p. 349-62.

43. Yang, H.C. and L.A. Pon, Actin cable dynamics in budding yeast. Proc Natl Acad Sci U S A, 2002. 99(2): p. 751-6. 
44. Riedl, J., et al., Lifeact: a versatile marker to visualize F-actin. Nat Methods, 2008. 5(7): p. 605-7.

45. Kumari, A., et al., Structural insights into actin filament recognition by commonly used cellular actin markers. EMBO J, 2020. 39(14): p. e104006.

46. Belyy, A., et al., Structure of the Lifeact-F-actin complex. PLoS Biol, 2020. 18(11): p. e3000925.

47. Timney, B.L., et al., Simple rules for passive diffusion through the nuclear pore complex. J Cell Biol, 2016. 215(1): p. 57-76.

48. Asakura, T., et al., Isolation and characterization of a novel actin filament-binding protein from Saccharomyces cerevisiae. Oncogene, 1998. 16(1): p. 121-30.

49. Coue, M., et al., Inhibition of actin polymerization by latrunculin A. FEBS Lett, 1987. 213(2): p. 316-8.

50. Ayscough, K.R., et al., High rates of actin filament turnover in budding yeast and roles for actin in establishment and maintenance of cell polarity revealed using the actin inhibitor latrunculin-A. J Cell Biol, 1997. 137(2): p. 399-416.

51. Fujiwara, I., et al., Latrunculin A Accelerates Actin Filament Depolymerization in Addition to Sequestering Actin Monomers. Curr Biol, 2018. 28(19): p. 3183-3192 e2.

52. Rog, O., S. Kohler, and A.F. Dernburg, The synaptonemal complex has liquid crystalline properties and spatially regulates meiotic recombination factors. Elife, 2017. 6.

53. Egelman, E.H., Reconstruction of helical filaments and tubes. Methods Enzymol, 2010. 482: p. 167-83.

54. Fromm, S.A. and C. Sachse, Cryo-EM Structure Determination Using Segmented Helical Image Reconstruction. Methods Enzymol, 2016. 579: p. 307-28.

55. He, S. and S.H.W. Scheres, Helical reconstruction in RELION. J Struct Biol, 2017. 198(3): p. 163-176.

56. Briegel, A., et al., The challenge of determining handedness in electron tomography and the use of DNA origami gold nanoparticle helices as molecular standards. J Struct Biol, 2013. 183(1): p. 95-8.

57. Pierson, J., et al., Improving the technique of vitreous cryo-sectioning for cryo-electron tomography: electrostatic charging for section attachment and implementation of an anti-contamination glove box. $\mathrm{J}$ Struct Biol, 2010. 169(2): p. 219-25.

58. Cai, S., et al., Natural chromatin is heterogeneous and selfassociates in vitro. Mol Biol Cell, 2018. 29(13): p. 1652-1663.

59. Ng, C.T., M. Ladinsky, and L. Gan, Serial Cryomicrotomy of Saccharomyces cerevisiae for Serial Electron Cryotomography. BioProtocol, 2020. 10(22).

60. Colaiacovo, M.P., et al., Synaptonemal complex assembly in C. elegans is dispensable for loading strand-exchange proteins but critical for proper completion of recombination. Dev Cell, 2003. 5(3): p. 463-74.

61. Schmekel, K., et al., The central region of the synaptonemal complex in Blaps cribrosa studied by electron microscope tomography. Chromosoma, 1993. 102(10): p. 669-81.

62. Cahoon, C.K., et al., Superresolution expansion microscopy reveals the three-dimensional organization of the Drosophila synaptonemal complex. Proc Natl Acad Sci U S A, 2017. 114(33): p. E6857-E6866.

63. La Cour, L.F. and B. Wells, Some morphological aspects of the synaptonemal complex in higher plants. Philos Trans R Soc Lond B Biol Sci, 1977. 277(955): p. 259-66.

64. Byers, B. and L. Goetsch, Behavior of spindles and spindle plaques in the cell cycle and conjugation of Saccharomyces cerevisiae. J Bacteriol, 1975. 124(1): p. 511-23.

65. Joti, Y., et al., Chromosomes without a $30-\mathrm{nm}$ chromatin fiber. Nucleus, 2012. 3(5): p. 404-10.

66. Mitov, M., Cholesteric liquid crystals in living matter. Soft Matter, 2017. 13(23): p. 4176-4209.
67. Kleckner, N., et al., A mechanical basis for chromosome function. Proc Natl Acad Sci U S A, 2004. 101(34): p. 12592-7.

68. Börner, G.V., N. Kleckner, and N. Hunter, Crossover/noncrossover differentiation, synaptonemal complex formation, and regulatory surveillance at the leptotene/zygotene transition of meiosis. Cell, 2004. 117(1): p. 29-45.

69. Benchling. Benchling [Biology Software]. 2021; Available from: https:// benchling.com.

70. Longtine, M.S., et al., Additional modules for versatile and economical PCR-based gene deletion and modification in Saccharomyces cerevisiae. Yeast, 1998. 14(10): p. 953-61.

71. Nishimura, K. and M.T. Kanemaki, Rapid Depletion of Budding Yeast Proteins via the Fusion of an Auxin-Inducible Degron (AID). Curr Protoc Cell Biol, 2014. 64: p. 209 1-16.

72. Lõoke, M., K. Kristjuhan, and A. Kristjuhan, Extraction of genomic DNA from yeasts for PCR-based applications. Biotechniques, 2011. 50(5): p. 325-8.

73. Gietz, R.D. and R.H. Schiestl, High-efficiency yeast transformation using the LiAc/SS carrier DNA/PEG method. Nat Protoc, 2007. 2(1): p. 31-4.

74. Yakovlev, S. and K.H. Downing, Freezing in sealed capillaries for preparation of frozen hydratedsections. J Microsc, 2011. 244(3): p. 235-47.

75. Ladinsky, M.S., J.M. Pierson, and J.R. McIntosh, Vitreous cryosectioning of cells facilitated by a micromanipulator. J Microsc, 2006. 224(Pt 2): p. 129-34.

76. Studer, D., et al., A new tool based on two micromanipulators facilitates the handling of ultrathin cryosection ribbons. J Struct Biol, 2014. 185(1): p. 125-8.

77. Mastronarde, D.N., Automated electron microscope tomography using robust prediction of specimen movements. J Struct Biol, 2005. 152(1): p. 36-51.

78. Kremer, J.R., D.N. Mastronarde, and J.R. Mclntosh, Computer visualization of three-dimensional image data using IMOD. J Struct Biol, 1996. 116(1): p. 71-6.

79. Mastronarde, D.N., Dual-axis tomography: an approach with alignment methods that preserve resolution. J Struct Biol, 1997. 120(3): p. 343-52.

80. Mastronarde, D.N. and S.R. Held, Automated tilt series alignment and tomographic reconstruction in IMOD. J Struct Biol, 2017. 197(2): p. 102-113.

81. Heymann, J.B. and D.M. Belnap, Bsoft: image processing and molecular modeling for electron microscopy. J Struct Biol, 2007. 157(1): p. 3-18.

82. Scheres, S.H., RELION: implementation of a Bayesian approach to cryo-EM structure determination. J Struct Biol, 2012. 180(3): p. 519-30.

83. Nicastro, D., et al., The molecular architecture of axonemes revealed by cryoelectron tomography. Science, 2006. 313(5789): p. 944-8.

84. Heumann, J.M. PEET. 201622 March 2017]; Available from: http:// bio3d.colorado.edu/PEET/.

85. Bharat, T.A., et al., Advances in Single-Particle Electron Cryomicroscopy Structure Determination applied to Sub-tomogram Averaging. Structure, 2015. 23(9): p. 1743-53.

86. Kimanius, D., et al., Accelerated cryo-EM structure determination with parallelisation using GPUs in RELION-2. Elife, 2016. 5.

87. Zivanov, J., et al., New tools for automated high-resolution cryo-EM structure determination in RELION-3. Elife, 2018. 7.

88. Pettersen, E.F., et al., UCSF Chimera--a visualization system for exploratory research and analysis. J Comput Chem, 2004. 25(13): p. 1605-12.

89. Schindelin, J., et al., Fiji: an open-source platform for biological-image analysis. Nat Methods, 2012. 9(7): p. 676-82. 
bioRxiv preprint doi: https://doi.org/10.1101/746982; this version posted May 2, 2021. The copyright holder for this preprint (which was not certified by peer review) is the author/funder, who has granted bioRxiv a license to display the preprint in perpetuity. It is made available under aCC-BY-NC-ND 4.0 International license.

90. Ben-Shem, A., et al., The structure of the eukaryotic ribosome at 3.0 A resolution. Science, 2011. 334(6062): p. 1524-9.

91. Iudin, A., et al., EMPIAR: a public archive for raw electron microscopy image data. Nat Methods, 2016. 13(5): p. 387-8. 


\section{Supplemental information}
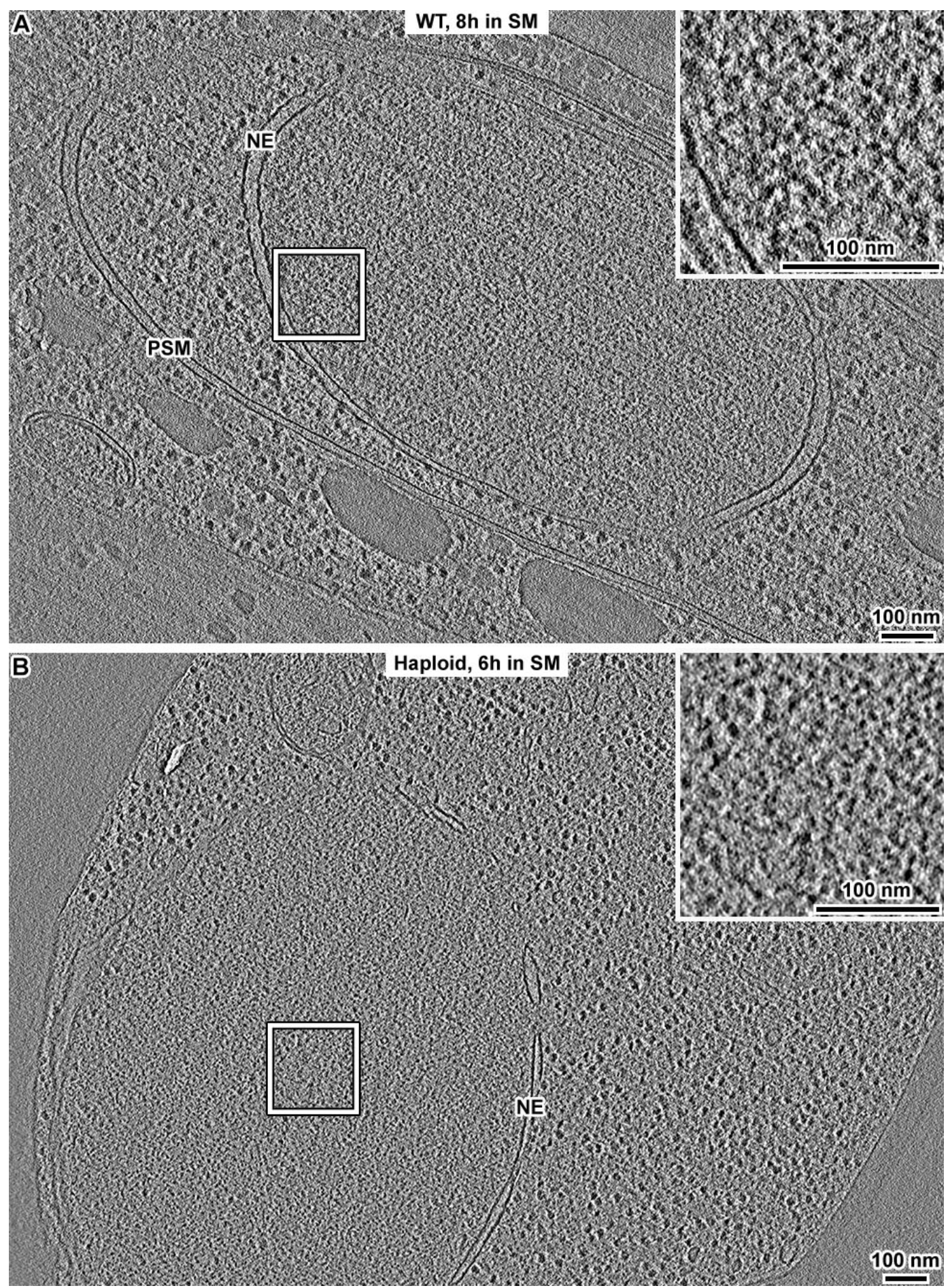

Figure S1. MTHs are not detected in late meiosis or starved haploid cells. (A) Volta cryotomographic slice (12 nm) of a diploid WT yeast cell after an 8-hour incubation in SM. PSM, prospore membrane; NE, nuclear envelope. (B) Volta cryotomographic slice (12 nm) of a haploid cell (strain LY2, W303 background) incubated 6 hours in SM. The insets show 3-fold enlargements of the nucleoplasm boxed in each panel. 

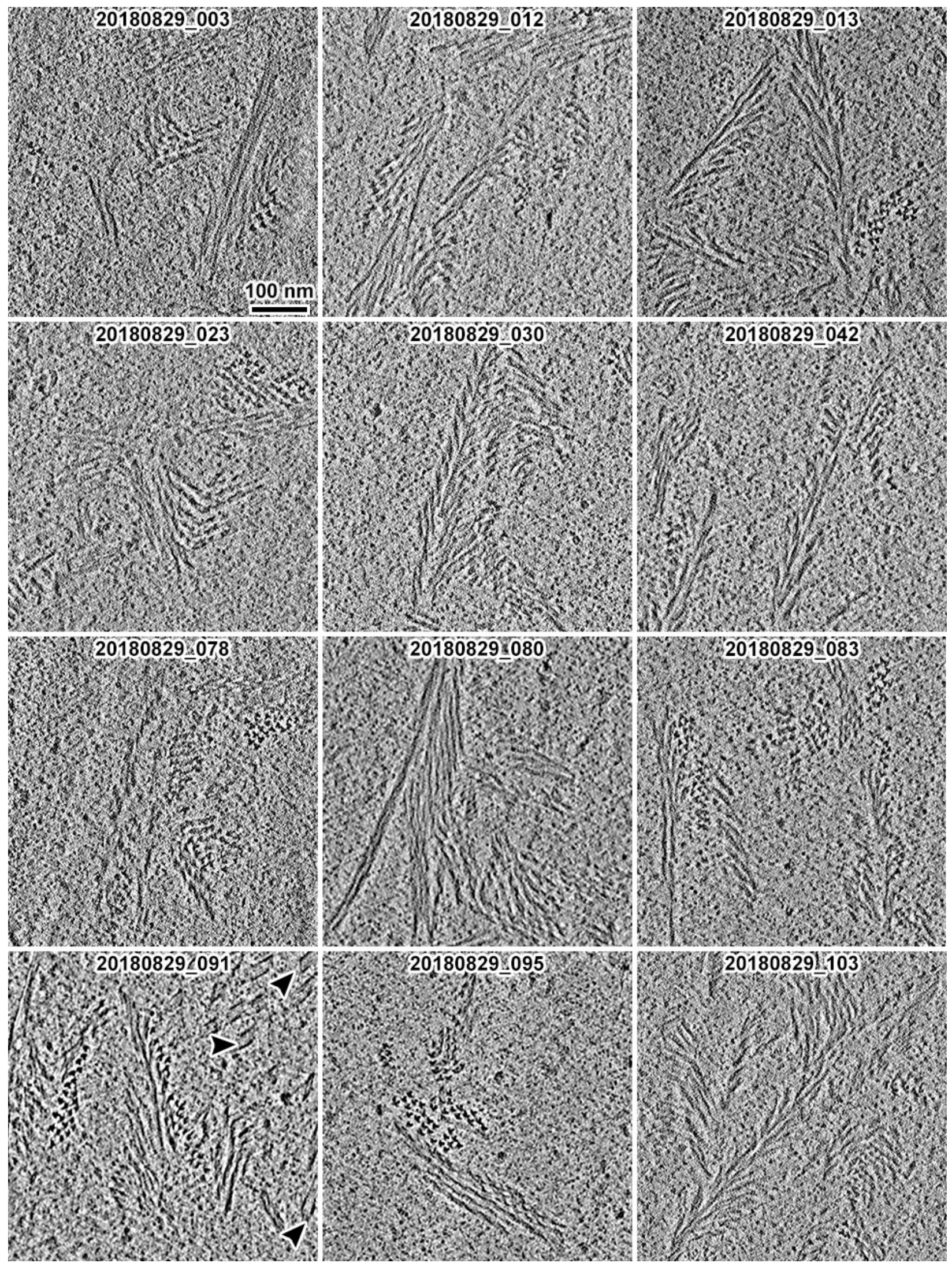
bioRxiv preprint doi: https://doi.org/10.1101/746982; this version posted May 2, 2021. The copyright holder for this preprint (which was not certified by peer review) is the author/funder, who has granted bioRxiv a license to display the preprint in perpetuity. It is made available under aCC-BY-NC-ND 4.0 International license.

Figure S2. Examples of MTH bundles in pachytene cell nuclei. Volta cryotomographic slices (10 nm) of 12 examples of $n d t 80 \Delta$ cell nuclei after 8 hours in SM. The arrowheads in the lower-left panel indicate nuclear microtubules. 
bioRxiv preprint doi: https://doi.org/10.1101/746982; this version posted May 2, 2021. The copyright holder for this preprint (which was not certified by peer review) is the author/funder, who has granted bioRxiv a license to display the preprint in perpetuity. It is made available under aCC-BY-NC-ND 4.0 International license.
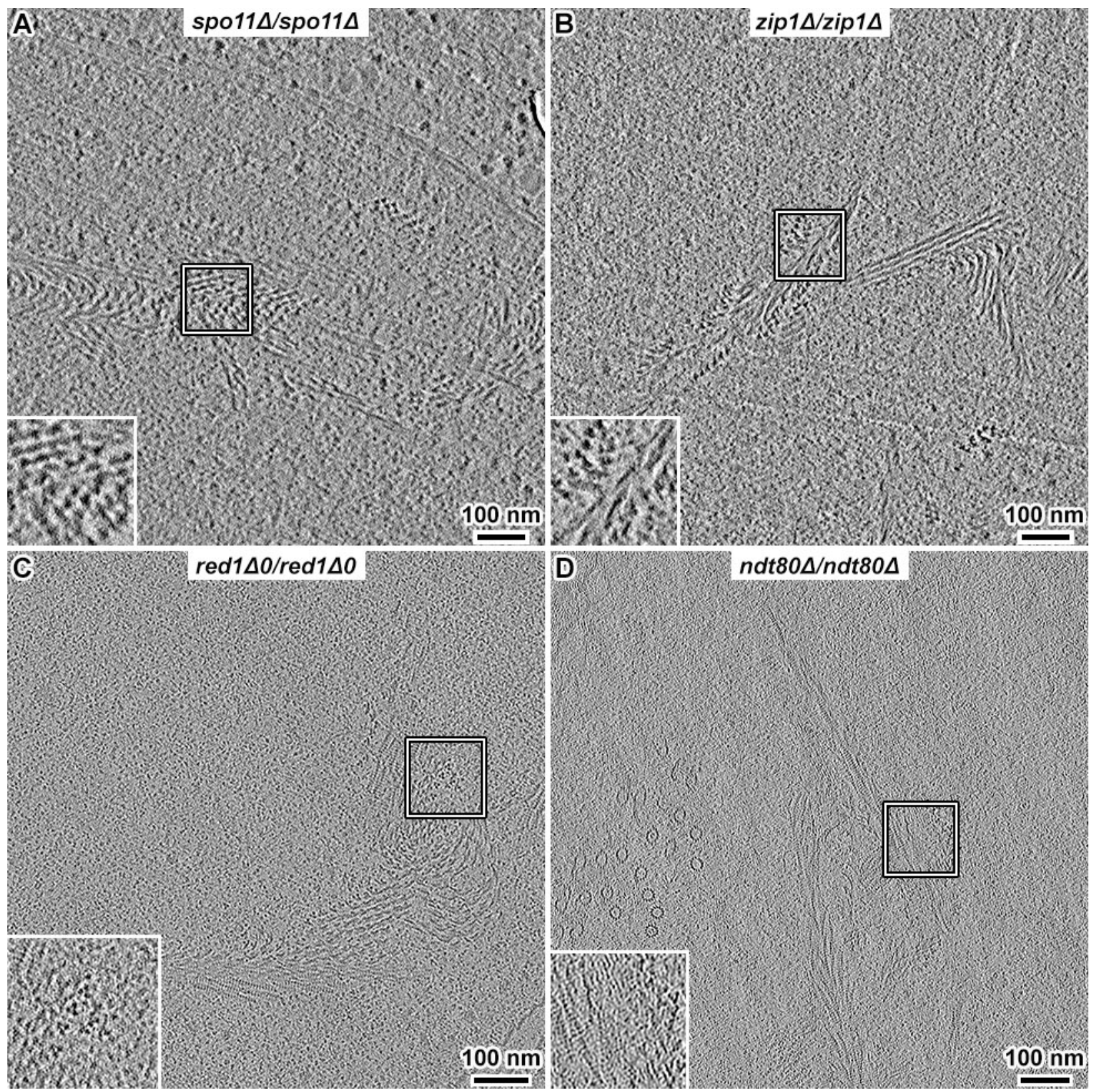

Figure S3. The MTH is present in null mutants of Spo11, Zip1, or Red1. (A) Volta cryotomographic slice (6 nm) of a spo11 $\Delta$ cell in SM, showing intra-nuclear MTH bundles. (B) Volta cryotomographic slice (12 nm) of a zip1 $\Delta$ cell in SM, showing MTH bundles inside the nucleus. (C) Defocus phase-contrast cryotomographic slice $(12 \mathrm{~nm})$ of a red1 $\Delta 0$ cell in SM, showing intra-nuclear MTH bundles. Insets show two-fold enlargements of the boxed areas. The contrast in panel $\mathrm{C}$ appears different from panels $\mathrm{A}+\mathrm{B}$ because of the different contrast mechanism and because the data was recorded on an electron-counting camera and by zero-loss energy filtering. This difference in contrast is also evident in (D) the $n d t 80 \Delta$ control cell cryotomogram, imaged in similar conditions as for panel $\mathrm{C}$. 
bioRxiv preprint doi: https://doi.org/10.1101/746982; this version posted May 2, 2021. The copyright holder for this preprint (which was not certified by peer review) is the author/funder, who has granted bioRxiv a license to display the preprint in perpetuity. It is made available under aCC-BY-NC-ND 4.0 International license.
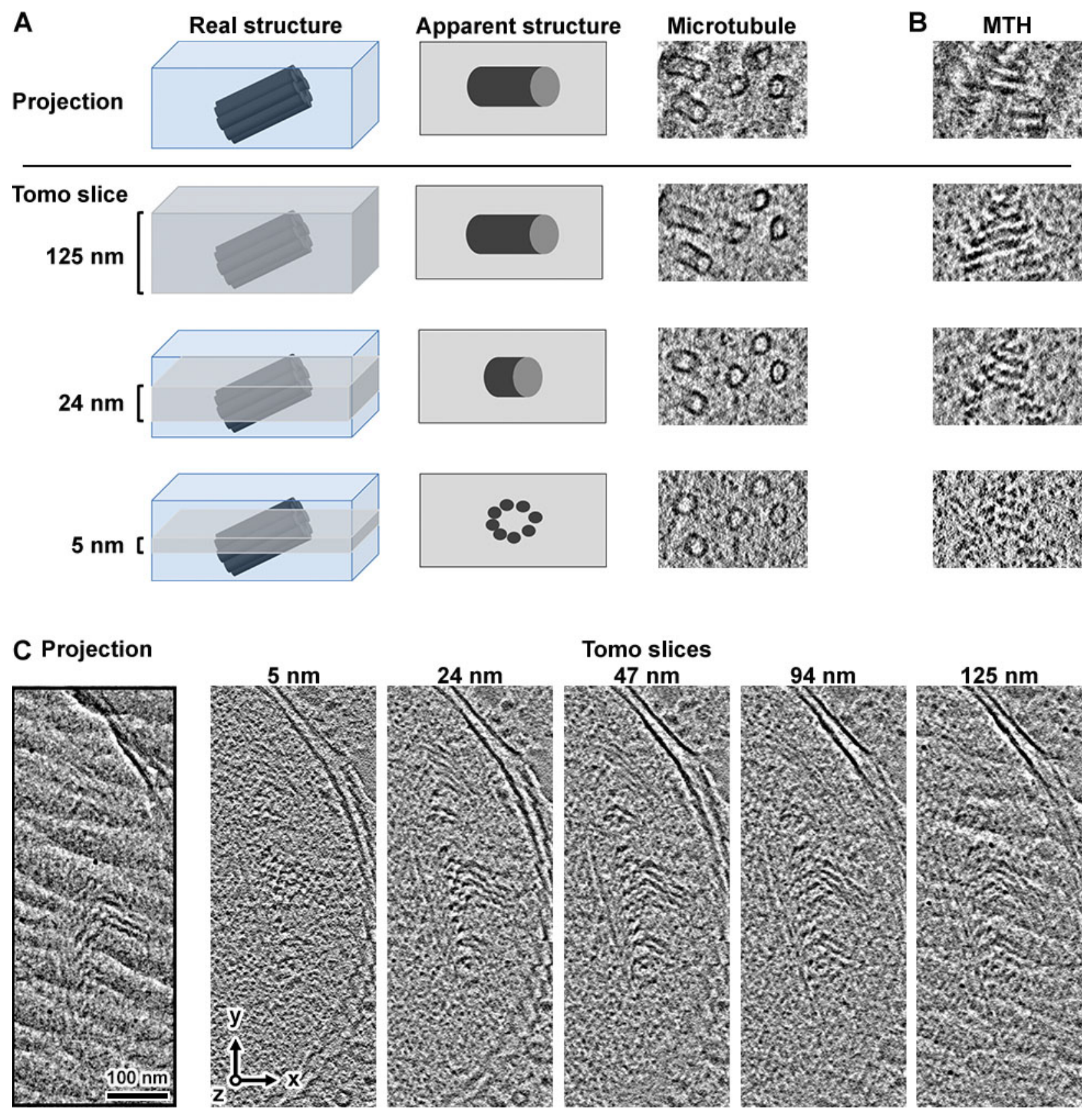

Figure S4. Comparison between tomographic slices and projections. (A) Cartoon of comparison between projection and tomographic slices of various thicknesses. Thinner tomographic slices reveal details like microtubule protofilaments. Thicker tomographic slices resemble projection images. (B) In some projections, contiguous MTH structures appear to orient approximately perpendicular (left-right) to the orientation of the filaments (out of the plane). (C) An MTH bundle position in a cell that has a chevronlike motif in projection. The thinner tomographic slices show that the underlying structure is a set of periodically packed MTHs that are oblique relative to the $Z$ axis. 
A

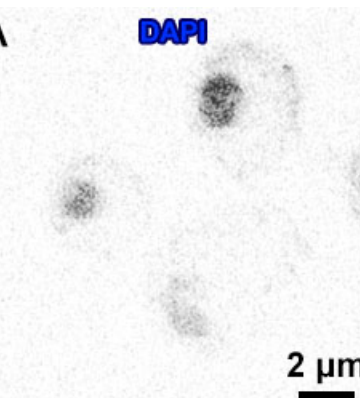

B

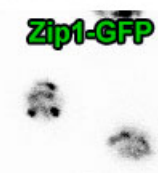

48

C

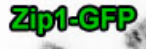

$2 \mu \mathrm{m}$

APD=타

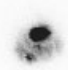

$2 \mu \mathrm{m}$

$\mu \mathrm{m}$

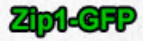
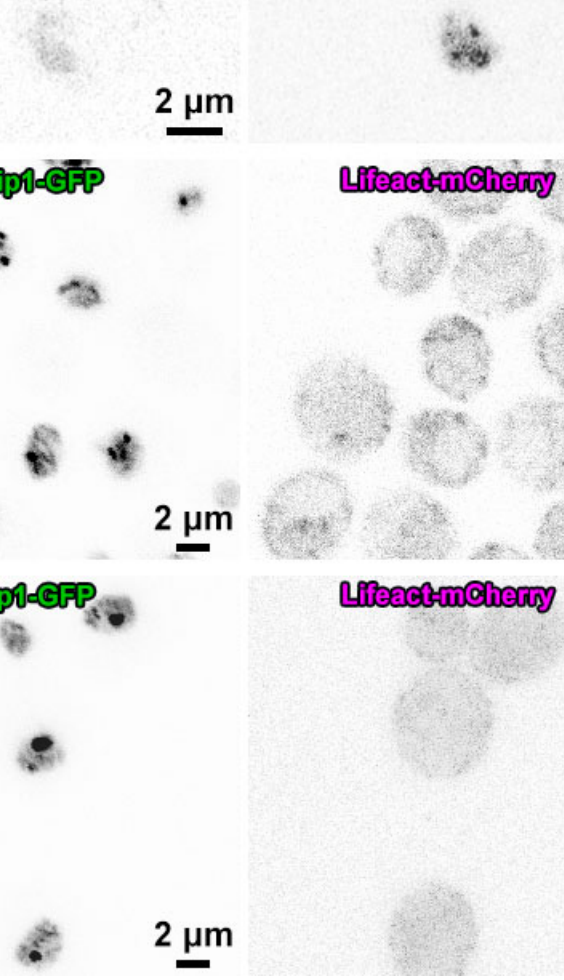

Liteactmotheny
Phalloidin
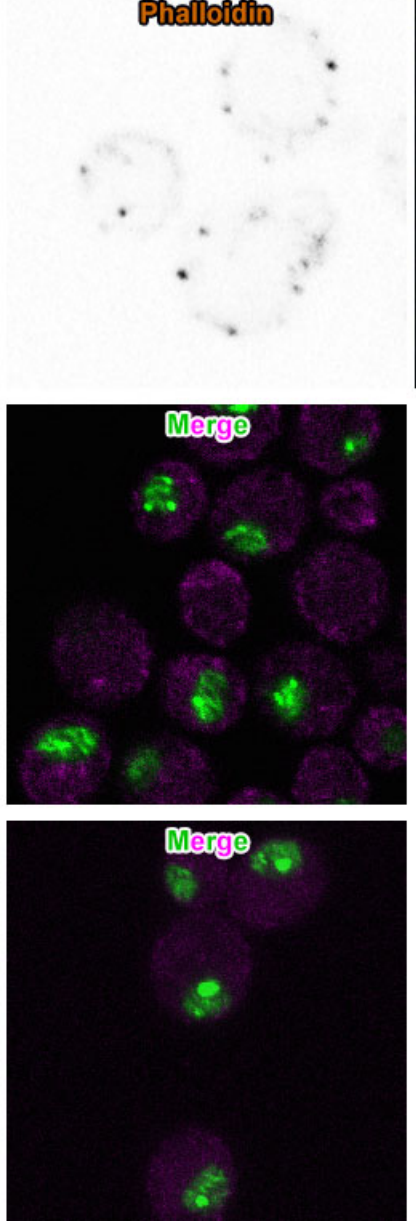

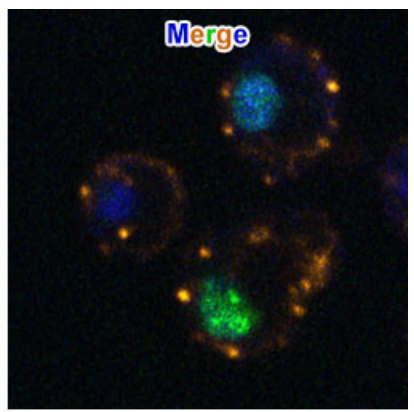

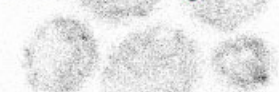

Figure S5. F-actin does not localize to nuclei in pachytene. (A) Fluorescence micrographs of pachytene-arrested EW104 cells after 6 hours in SM. SCs are marked by Zip1-GFP. Phalloidin-stained F-actin does not co-localize with DAPI-stained chromatin or Zip1-GFP. (B) Confocal slices of pachytene-arrested LGY0069 cells, which express Zip1-GFP (green) and Lifeact-mCherry (magenta). (C) Maximum-intensity projections through the nuclei of LGY0069 cells. 
bioRxiv preprint doi: https://doi.org/10.1101/746982; this version posted May 2, 2021. The copyright holder for this preprint (which was not certified by peer review) is the author/funder, who has granted bioRxiv a license to display the preprint in perpetuity. It is made available under aCC-BY-NC-ND 4.0 International license.

A
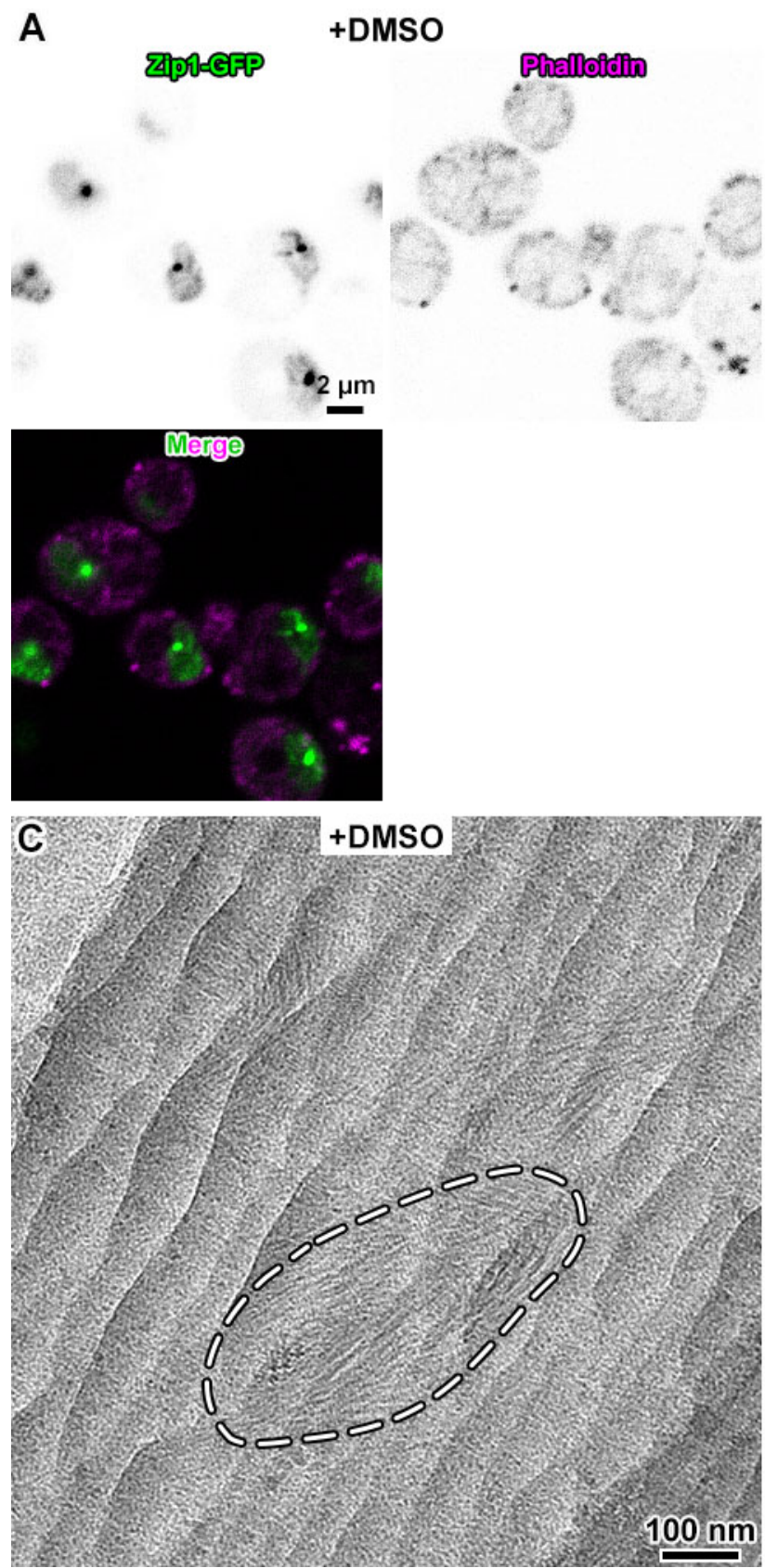

B

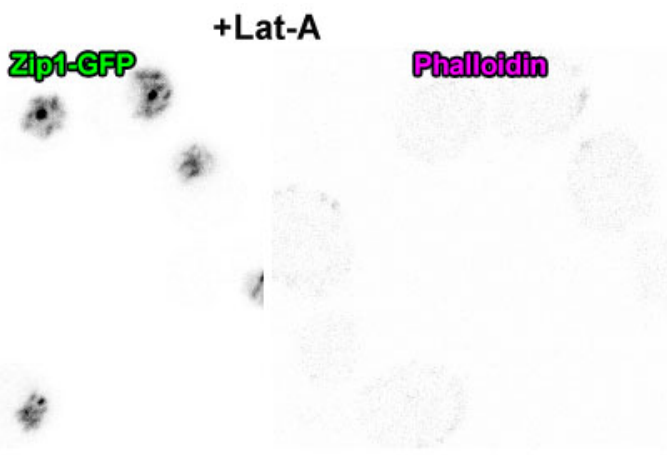

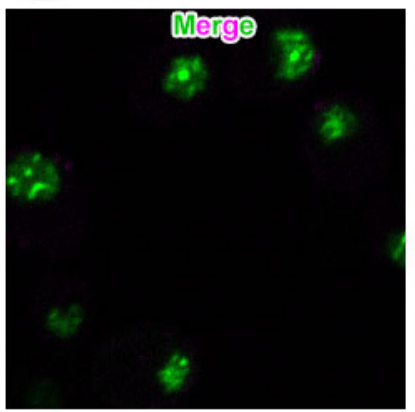

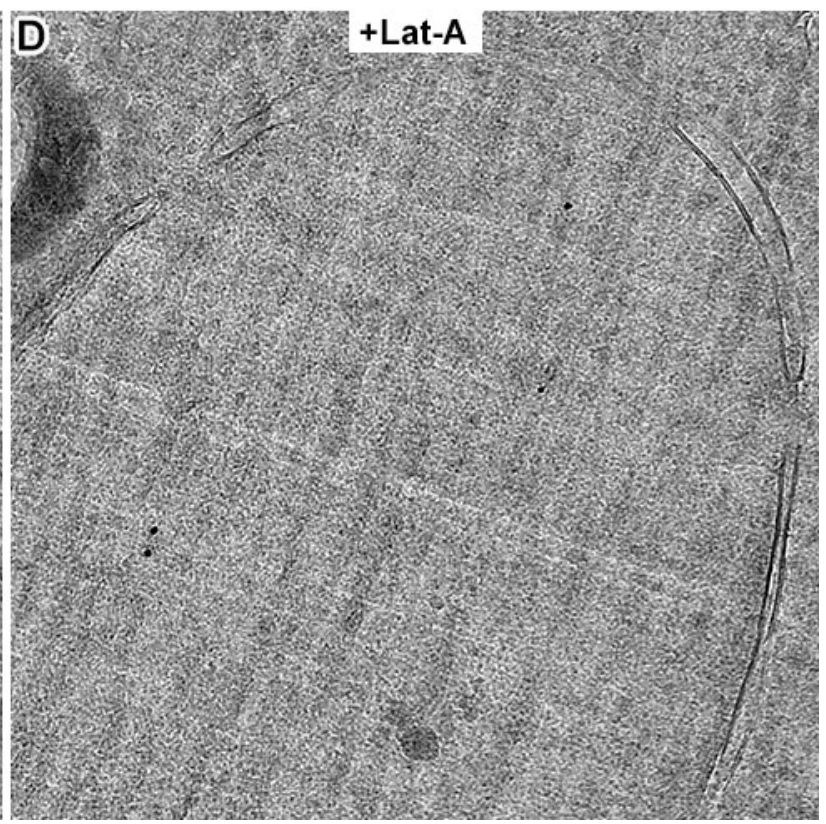

Figure S6. MTH assembly is dependent on F-actin polymerization. Fluorescence microscopy of (A) DMSO-treated and (B) Latrunculin A-treated EW104 pachytene cells. (C) Projection cryo-EM image of DMSO-treated EW104 (ndt80A) cells, showing MTH bundles inside the nucleus. One set of MTH bundles is enclosed in the dashed oval. (D) Projection cryo-EM image of Latrunculin Atreated EW104 ndt80 $\Delta$ cells. In panels $C$ and D, the linear pattern running along the diagonal form the upper left to the lower right is from knife marks. In panel C, the wavy patterns running along the 2 o'clock to 8 o'clock diagonal are from cryosection crevassing. 


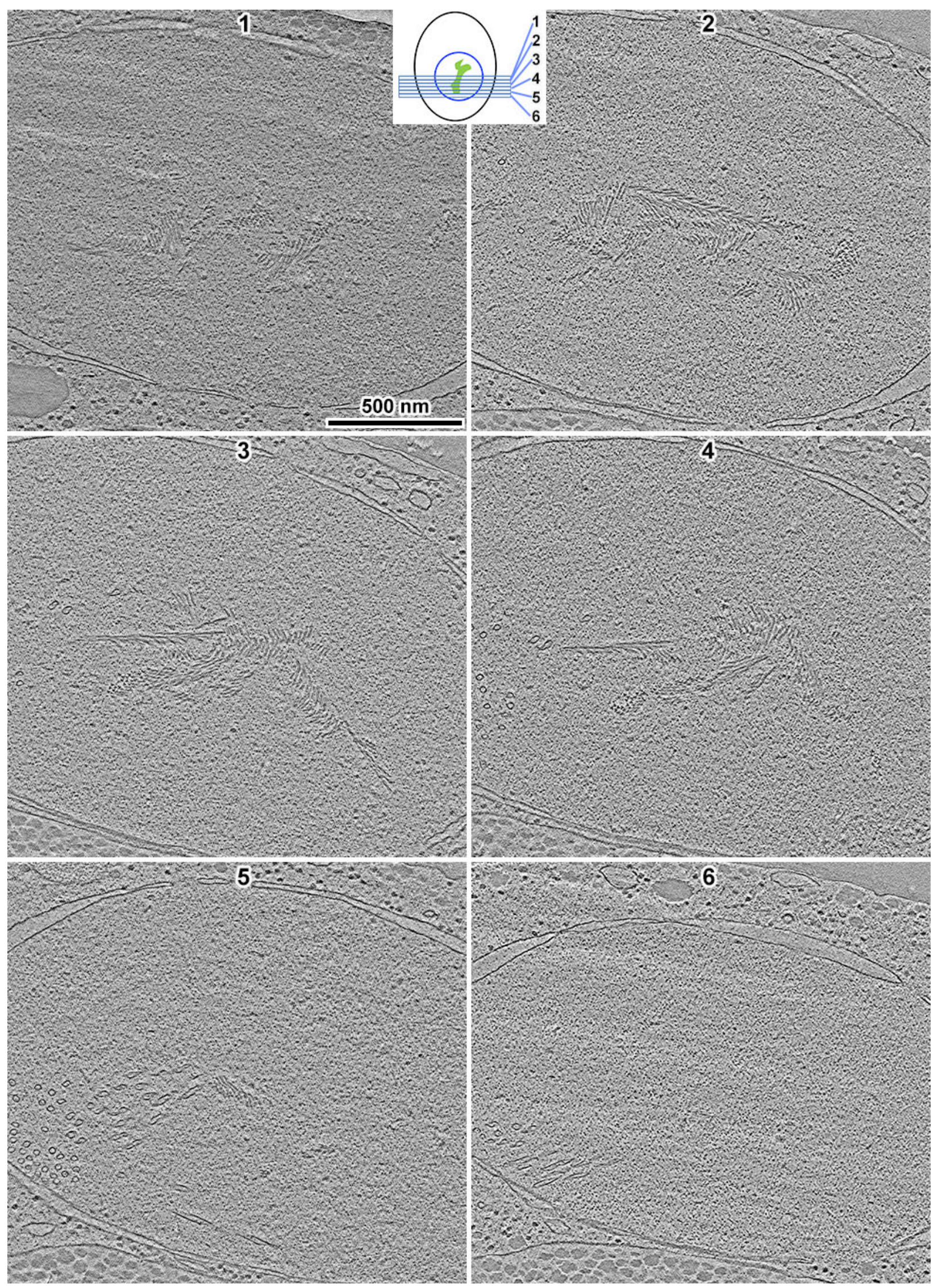


A

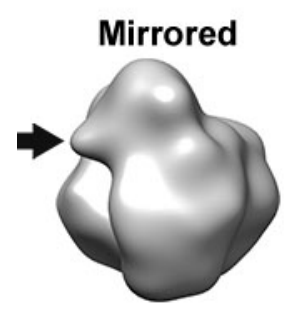

Simulated

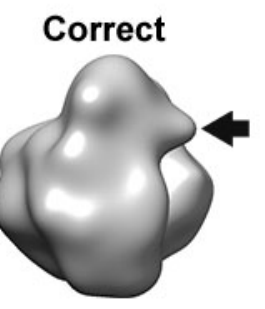

B Average

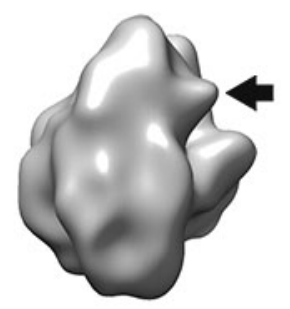

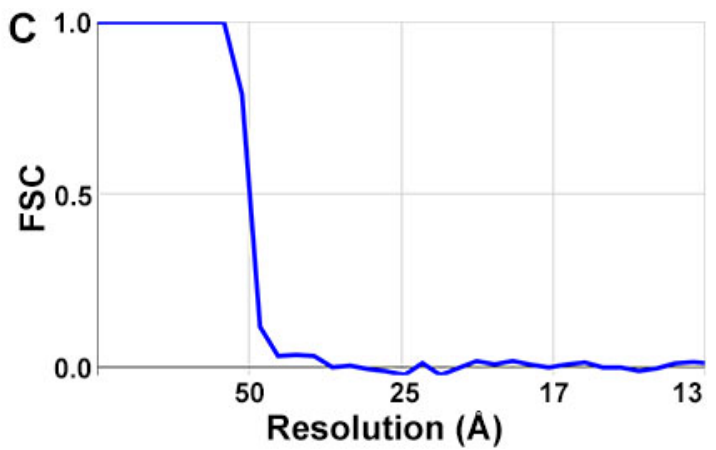

Figure S7. The cryotomograms have the correct hand. (A) Density map of the $80 \mathrm{~S}$ yeast ribosome [2], simulated at $35 \AA$ resolution with the wrong hand (mirrored) and correct one. The "beak" motif is indicated by the arrow. (B) Subtomogram average of cytoplasmic ribosomes from $n d t 80 \Delta$ cells. (C) Fourier shell correlation (FSC) plot of the subtomogram average in panel $\mathrm{B}$. The resolution is $\sim 50 \AA$, based on the "Gold standard" FSC $=0.5$ criterion. 


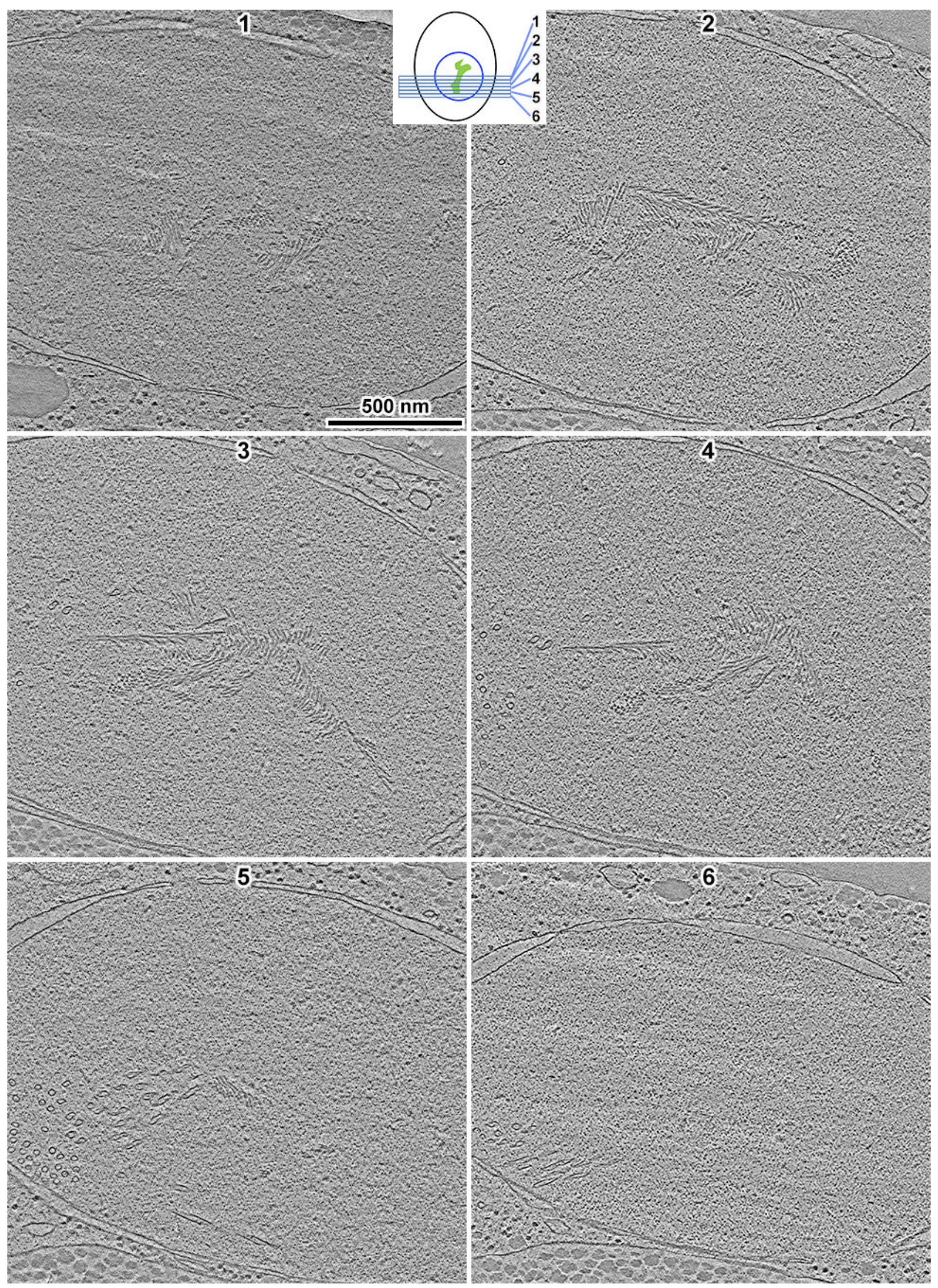


Figure S8. MTH bundles are extensive throughout the cell nucleus. Volta cryotomographic slices of six sequential cryosections of a single ndt80 $\Delta$ cell, isolated after 8 hours in SM. The schematic (not to scale) shows the relationship between the numbered cryosections and the cytology. Major features are the cell nucleus (blue circle) and the MTH bundles (green blob). The MTHs are located in the center of the nucleus while the spindle is anchored at the lower left, with many nuclear microtubules visible in cryosections 4,5 , and 6. 
bioRxiv preprint doi: https://doi.org/10.1101/746982; this version posted May 2, 2021. The copyright holder for this preprint (which was not certified by peer review) is the author/funder, who has granted bioRxiv a license to display the preprint in perpetuity. It is made available under aCC-BY-NC-ND 4.0 International license.

Movie S1. In situ organization of the yeast MTH bundle. This movie shows a representative MTH bundle in a WT cell (NKY611), a 3D model of the MTH bundle, and a subtomogram average of an MTH segment. 
bioRxiv preprint doi: https://doi.org/10.1101/746982; this version posted May 2, 2021. The copyright holder for this preprint (which was not certified by peer review) is the author/funder, who has granted bioRxiv a license to display the preprint in perpetuity. It is made available under aCC-BY-NC-ND 4.0 International license.

Table S1. Strains used.

\begin{tabular}{|c|c|c|c|}
\hline Strain & Parent & Genotype & Source \\
\hline NKY611 & - & SK1; diploid & [3] \\
\hline DK428 * & - & Zip1::GFP/Zip1::GFP & [4] \\
\hline EW104 & $\begin{array}{l}\text { NKY2292, } \\
\text { NKY2293 }\end{array}$ & 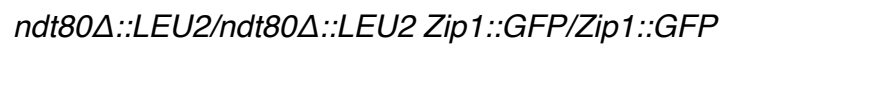 & [1] \\
\hline LY2 & - & W303; haploid & Lacefield \\
\hline NKY2535 & - & 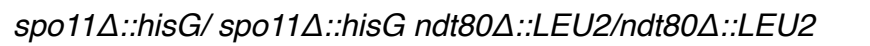 & [3] \\
\hline NKY2460 & - & zip1 $\triangle:: L E U 2 / z i p 1 \Delta:: L E U 2$ & [3] \\
\hline LGY0068 & $\begin{array}{l}\text { NKY2292, } \\
\text { NKY2293 }\end{array}$ & ndt80 $\Delta:: L E U 2 /$ ndt80 $\triangle:: L E U 2$ red1 $\triangle 0:: U R A 3 /$ red1 $\triangle 0:: K a n M X$ & This paper \\
\hline LGY0069 & EW104 & $\begin{array}{l}\text { ndt80 }::: L E U 2 / n d t 80 \triangle:: L E U 2 \text { Zip1::GFP/Zip1::GFP ABP140/ } \\
\text { ABP140::Lifeact-yomCherry }\end{array}$ & This paper \\
\hline
\end{tabular}

* DK428 was formerly known as HW655 
Table S2. Primers, 5' $\rightarrow$ 3'.

\begin{tabular}{|c|c|}
\hline \multicolumn{2}{|l|}{ Editing } \\
\hline $\operatorname{Red} 1 \Delta \theta$ KanMX F & $\begin{array}{l}\text { CATTAAAGGTAATAAGAAAAATAGAACAAAGAATTTTTAAGCACAGGACCACAAAGGGACAGCAA } \\
\text { ATACGGTGATAAGAGACATGGAGGCCCAGAATACC }\end{array}$ \\
\hline $\operatorname{Red} 1 \Delta \theta$ KanMX R & $\begin{array}{l}\text { CGAACATGAATAAGCTTGCCTATATTACTTTTATTTAGCCATCTTAAATCTAAAAAGAATTGCGTA } \\
\text { TATGTATACTATCAGTATAGCGACCAGCATTCAC }\end{array}$ \\
\hline Red1 $\Delta 0$ URA3 $\mathrm{F}$ & $\begin{array}{l}\text { GAATAAGCTTGCCTATATTACTTTTATTAGCCATCTTAAATCTAAAAAGAATTGCGTATATGTAT } \\
\text { ACTATCAGTATAGCGACCAGCATTCACATACG }\end{array}$ \\
\hline Red1 $\Delta 0$ URA3 R & $\begin{array}{l}\text { GGTAATAAGAAAAATAGAACAAAGAATTTTTAAGCACAGGACCACAAAGGGACAGCAAATACGGT } \\
\text { GATAAGAGACATGGAGGCCCAGAATACCCTCC }\end{array}$ \\
\hline Lifeact-yomCherry-KanMX F & $\begin{array}{l}\text { TGGGTGTCGCAGATTTGATCAAGAAATTCGAAAGCATCTCAAAGGAAGAAGGTGCTGGTTTAATT } \\
\text { AACATGG }\end{array}$ \\
\hline Lifeact-yomCherry-KanMX R & $\begin{array}{l}\text { CGTTTGATTTGAGAGGCTTTGATGAACTGTTTGTATCAACGGTAGCATCGCCCAGTATAGCGACC } \\
\text { AGCATTCAC }\end{array}$ \\
\hline \multicolumn{2}{|r|}{ (1) } \\
\hline $\operatorname{Red} 1 \Delta \theta$ VF1 & GGAAAATCCAGTCAGTTGGAAATG \\
\hline $\operatorname{Red} 1 \Delta \theta$ VR1 & CCCTCGTTTTGTTAAATAAGAGTGC \\
\hline $\operatorname{Red} 1 \Delta \theta$ VF2 & CAATGACAAATCACAACAGTTTTCC \\
\hline $\operatorname{Red} 1 \Delta \theta$ VR2 & CAACGTCAATTGATGCACATAAATTG \\
\hline $\operatorname{Red} 1 \Delta \theta$ VF3 & GAGGATTGTTTGGTAAAGGAAGAG \\
\hline $\operatorname{Red} 1 \Delta \theta$ VR3 & GAATCCATTTTTTGCTGCTCTTTTATG \\
\hline $\operatorname{Red} 1 \Delta \theta$ VF4 & GCGAGTGATTTTGATGACGAG \\
\hline $\operatorname{Red} 1 \Delta \theta$ VR4 & CTGTAACATCATTGGCAACGC \\
\hline Lifeact-mCherry VF1 & AGAAGTGGCACTATAGCTGTG \\
\hline Lifeact-mCherry VR1 & GTACAGTTCATCCATACCAC \\
\hline Lifeact-mCherry VF2 & CCATGGGTAAGGAAAAGAC \\
\hline Lifeact-mCherry VR2 & CTCTTGTTGATGCAATTCTTTGG \\
\hline \multicolumn{2}{|l|}{ Sequencing } \\
\hline Red1 deletion_conf F1 & CAAAACATTCACATCATTCGTGAAG \\
\hline Red1 deletion_conf R2 & CCGGGATCTAGAAATATTTAATTGAGG \\
\hline URA3 within REV & ATTGTCAGTACTGATTATAATTGG \\
\hline Red1: : KanMX conf FWD2 & СCTTACCCATGGTTGTTTAT \\
\hline
\end{tabular}


bioRxiv preprint doi: https://doi.org/10.1101/746982; this version posted May 2, 2021. The copyright holder for this preprint (which was not certified by peer review) is the author/funder, who has granted bioRxiv a license to display the preprint in perpetuity. It is made available under aCC-BY-NC-ND 4.0 International license.

Table S3. Cryo-ET details.

Sample preparation

EM grids

Cryomicrotome

Attachment device

Micromanipulators

Cryomicrotome feed

\section{Cryo-ET data collection}

Microscope

Energy

Camera: recording mode

Energy filter width

Tomography software

Unbinned pixel size

Contrast mechanism

Defocus (nominal)

Cumulative dose

Dose fractionation

Tilt range

Tilt increment

\section{Cryo-ET data analysis}

Tomogram processing

Template matching

Reference creation

Mask creation

Subtomogram analysis

Tomogram visualization

Auxiliary scripts

Calculations

Figure/movie editing
Continuous Carbon

UC7/FC7

Crion

Leica micromanipulator; Narishige MN-151-S

70 or $100 \mathrm{~nm}$

Titan Krios

$300 \mathrm{keV}$

Falcon II: integration

K3-GIF: super-resolution, movie frames

$20 \mathrm{eV}$

TFS Tomo4 and SerialEM

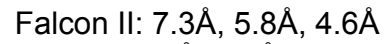

K3-GIF: $3.4 \AA, 4.6 \AA$

Volta phase contrast \& defocus phase contrast

Volta phase contrast: $-0.5 \mu \mathrm{m}$

Defocus phase contrast: $-9 \mu \mathrm{m}$

$60-120 e^{-/} \AA^{2}$

$1 /$ cosine

$\pm 60^{\circ}$, bidirectional, negative angles first; dose-symmetric

$2^{\circ}$

IMOD 4.10.22 beta

PEET 1.13.0

Bsoft 1.8.8

Bsoft 1.8.8, RELION 3.0.7

RELION 3.0.7

UCSF Chimera 1.13.1, IMOD 4.10.22 beta

https://github.com/anaphaze/ot-tools

Google sheets, FIJI

Adobe Photoshop, Illustrator, and Premiere Pro CC 
Table S4. Cryo-EM details.

\begin{tabular}{|c|c|c|c|c|c|c|}
\hline Dataset & Strain & $\begin{array}{l}\text { SM time, } \\
\text { treatment }\end{array}$ & $\begin{array}{l}\text { Figures, } \\
\text { analysis }\end{array}$ & Dose & $\begin{array}{l}\text { Pixel } \\
\text { size }(\AA)\end{array}$ & $\begin{array}{l}\Delta f \\
(\mu \mathrm{m})\end{array}$ \\
\hline \multicolumn{7}{|l|}{ Cryotomograms } \\
\hline 20180629_139 & NKY611 & $\mathrm{Oh}$ & $2 \mathrm{~A}$ & 100 & 7.3 & 0.5 \\
\hline 20180816_032 & DK428 & $2 \mathrm{~h}$ & $2 B$ & 100 & 5.8 & 0.5 \\
\hline 20180731_029 & DK428 & $4 \mathrm{~h}$ & $2 \mathrm{C}$ & 100 & 7.3 & 0.5 \\
\hline 20181204_025 & DK428 & $6 \mathrm{~h}$ & $2 \mathrm{D}, 6 \mathrm{~A}$ & 100 & 5.8 & 0.5 \\
\hline 20180731_087 & EW104 & $8 \mathrm{~h}$ & $3 C$ & 100 & 4.6 & 0.5 \\
\hline 20181204_001 & DK428 & $6 \mathrm{~h}$ & $4 \mathrm{~B}$ & 100 & 5.8 & 0.5 \\
\hline 20190322_5hx_017 & DK428 & $6 h,+5 \% h x$ & 4C, STA & 70 & 4.6 & 0.5 \\
\hline 20181204_7hx_021 & DK428 & $6 \mathrm{~h},+7 \% \mathrm{hx}$ & $4 \mathrm{D}$ & 100 & 5.8 & 0.5 \\
\hline 20200728_wsh_025 & DK428 & $6 \mathrm{~h},+7 \% \mathrm{hx},+\mathrm{SM}$ & 4E & 100 & 5.8 & 0.5 \\
\hline 20190429_037 & NKY611 & $4 \mathrm{~h}$ & $5 A+B ; 6 B+D, m o l$ & 100 & 5.8 & 0.5 \\
\hline 20190429_076 & NKY611 & $4 \mathrm{~h}$ & $6 \mathrm{C}, \mathrm{STA}$ & 100 & 5.8 & 0.5 \\
\hline 20190109_035 & DK428 & $8 \mathrm{~h}$ & S1A & 100 & 5.8 & 0.5 \\
\hline 20190213_020 & LY2 & $6 \mathrm{~h}$ & S1B & 100 & 11.7 & 0.5 \\
\hline 20180829_003 & EW104 & $8 \mathrm{~h}$ & $\mathrm{~S} 2$ & 100 & 5.8 & 0.5 \\
\hline 20180829_012 & EW104 & $8 \mathrm{~h}$ & $\mathrm{~S} 2$ & 100 & 5.8 & 0.5 \\
\hline 20180829_013 & EW104 & $8 \mathrm{~h}$ & $\mathrm{~S} 2$ & 100 & 5.8 & 0.5 \\
\hline 20180829_023 & EW104 & $8 \mathrm{~h}$ & $\mathrm{~S} 2$ & 100 & 5.8 & 0.5 \\
\hline 20180829_030 & EW104 & $8 \mathrm{~h}$ & S2, S8 \#2, STA & 100 & 5.8 & 0.5 \\
\hline 20180829_042 & EW104 & $8 \mathrm{~h}$ & S2, STA & 100 & 5.8 & 0.5 \\
\hline 20180829_078 & EW104 & $8 \mathrm{~h}$ & S2, STA & 100 & 5.8 & 0.5 \\
\hline 20180829_080 & EW104 & $8 \mathrm{~h}$ & S2, STA & 100 & 5.8 & 0.5 \\
\hline 20180829_083 & EW104 & $8 \mathrm{~h}$ & S2, STA & 100 & 5.8 & 0.5 \\
\hline 20180829_091 & EW104 & $8 \mathrm{~h}$ & S2, STA & 100 & 5.8 & 0.5 \\
\hline 20180829_095 & EW104 & $8 \mathrm{~h}$ & S2, STA & 100 & 5.8 & 0.5 \\
\hline 20180829_103 & EW104 & $8 \mathrm{~h}$ & $\mathrm{~S} 2$ & 100 & 5.8 & 0.5 \\
\hline 20200325_009 & NKY2535 & $6 \mathrm{~h}$ & S3A & 100 & 5.8 & 0.5 \\
\hline 20200618_003 & NKY2460 & $6 \mathrm{~h}$ & S3B & 100 & 5.8 & 0.5 \\
\hline 20201214_003 & LGY0068 & $8 \mathrm{~h}$ & S3C & 100 & 3.4 & 9 \\
\hline 20200304_020 & EW104 & $8 \mathrm{~h}$ & S3D & 100 & 4.6 & 7 \\
\hline 20181204_071 & DK428 & $6 \mathrm{~h}$ & S4C & 100 & 5.8 & 0.5 \\
\hline 20180829_024 & EW104 & $8 \mathrm{~h}$ & S8 \#1, STA & 100 & 5.8 & 0.5 \\
\hline 20180829_058 & EW104 & $8 \mathrm{~h}$ & S8 \#3, STA & 100 & 5.8 & 0.5 \\
\hline 20180829_066 & EW104 & $8 \mathrm{~h}$ & S8 \#4, STA & 100 & 5.8 & 0.5 \\
\hline 20180829_075 & EW104 & $8 \mathrm{~h}$ & S8 \#5, STA & 100 & 5.8 & 0.5 \\
\hline 20180829_088 & EW104 & $8 \mathrm{~h}$ & S8 \#6 & 100 & 5.8 & 0.5 \\
\hline 20180829_037 & EW104 & $8 \mathrm{~h}$ & STA & 100 & 5.8 & 0.5 \\
\hline 20180829_038 & EW104 & $8 \mathrm{~h}$ & STA & 100 & 5.8 & 0.5 \\
\hline 20180829_045 & EW104 & $8 \mathrm{~h}$ & STA & 100 & 5.8 & 0.5 \\
\hline 20180829_048 & EW104 & $8 \mathrm{~h}$ & STA & 100 & 5.8 & 0.5 \\
\hline 20180829_085 & EW104 & $8 \mathrm{~h}$ & STA & 100 & 5.8 & 0.5 \\
\hline 20180829_086 & EW104 & $8 \mathrm{~h}$ & STA & 100 & 5.8 & 0.5 \\
\hline 20190429_003 & NKY611 & $4 \mathrm{~h}$ & STA & 100 & 5.8 & 0.5 \\
\hline 20190429_007 & NKY611 & $4 \mathrm{~h}$ & STA & 100 & 5.8 & 0.5 \\
\hline 20190429_019 & NKY611 & $4 \mathrm{~h}$ & STA & 100 & 5.8 & 0.5 \\
\hline 20190429_020 & NKY611 & $4 \mathrm{~h}$ & STA & 100 & 5.8 & 0.5 \\
\hline 20190429_029 & NKY611 & $4 \mathrm{~h}$ & STA & 100 & 5.8 & 0.5 \\
\hline 20190605_040 & NKY611 & $4 \mathrm{~h}$ & STA & 100 & 4.6 & 0.5 \\
\hline 20190605_041 & NKY611 & $4 \mathrm{~h}$ & STA & 100 & 4.6 & 0.5 \\
\hline 20190605_044 & NKY611 & $4 \mathrm{~h}$ & STA & 100 & 4.6 & 0.5 \\
\hline 20190605_077 & NKY611 & $4 \mathrm{~h}$ & STA & 100 & 4.6 & 0.5 \\
\hline 20190605_084 & NKY611 & $4 \mathrm{~h}$ & STA & 100 & 4.6 & 0.5 \\
\hline
\end{tabular}


bioRxiv preprint doi: https://doi.org/10.1101/746982; this version posted May 2, 2021. The copyright holder for this preprint (which was not certified by peer review) is the author/funder, who has granted bioRxiv a license to display the preprint in perpetuity. It is made available under aCC-BY-NC-ND 4.0 International license.

\begin{tabular}{lllllll} 
20190605_085 & NKY611 & $4 \mathrm{~h}$ & STA & 100 & 4.6 & 0.5 \\
20190605_086 & NKY611 & $4 \mathrm{~h}$ & STA & 100 & 4.6 & 0.5 \\
20190605_090 & NKY611 & $4 \mathrm{~h}$ & STA & 100 & 4.6 & 0.5 \\
20190322_5hx_001 & DK428 & $6 \mathrm{~h} /+5 \% \mathrm{hx}$ & STA & 70 & 4.6 & 0.5 \\
20190322_5hx_003 & DK428 & $6 \mathrm{~h} /+5 \% \mathrm{hx}$ & STA & 70 & 4.6 & 0.5 \\
20190322_5hx_004 & DK428 & $6 \mathrm{~h} /+5 \% \mathrm{hx}$ & STA & 70 & 4.6 & 0.5 \\
20190322_5hx_008 & DK428 & $6 \mathrm{~h} /+5 \% \mathrm{hx}$ & STA & 70 & 4.6 & 0.5 \\
20190322_5hx_035 & DK428 & $6 \mathrm{~h} /+5 \% \mathrm{hx}$ & STA & 70 & 4.6 & 0.5 \\
20190322_5hx_040 & DK428 & $6 \mathrm{~h} /+5 \% \mathrm{hx}$ & STA & 70 & 4.6 & 0.5 \\
20190322_5hx_041 & DK428 & $6 \mathrm{~h} /+5 \% \mathrm{hx}$ & STA & 70 & 4.6 & 0.5 \\
& & & & & & \\
Projection images & & & & & & \\
DMSO & EW104 & $6 \mathrm{~h}+2 \mathrm{~h}$ DMSO & S6 & 14 & 3.4 & 10 \\
Lat-A & EW104 & $6 \mathrm{~h}+2 \mathrm{~h}$ Lat-A & S6 & 14 & 3.4 & 10 \\
Haploid & LY2 & $6 \mathrm{~h}$ & S1 & 10 & 7.3 & 0.5 \\
\hline
\end{tabular}

The cryo-ET data from this table were deposited as EMPIAR-10670. NKY611 = wild type; DK428 = wild type + Zip1-GFP; EW104 =

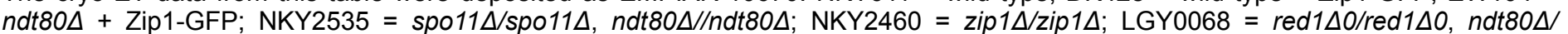
$n d t 80 \Delta$. SM time = duration in sporulation medium. $\mathrm{hx}=1,6$-hexanediol. STA = subtomogram averaging analysis. Dose, in electrons $/$ A2. Nominal underfocus $(\Delta f)$ values are reported. Volta phase contrast data was acquired at $0.5 \mu \mathrm{m}$ underfocus. 
bioRxiv preprint doi: https://doi.org/10.1101/746982; this version posted May 2, 2021. The copyright holder for this preprint (which was not certified by peer review) is the author/funder, who has granted bioRxiv a license to display the preprint in perpetuity. It is made available under aCC-BY-NC-ND 4.0 International license.

Table S5. Template-matching details.

\begin{tabular}{lllllll}
\hline Complex & Reference & $\begin{array}{l}\text { Grid } \\
\text { spacing }\end{array}$ & $\begin{array}{l}\text { Angular } \\
\text { steps } \dagger\end{array}$ & $\begin{array}{l}\text { CC } \\
\text { cutoff }\end{array}$ & $\begin{array}{l}\text { low-pass overlap } \\
\text { filter }\end{array}$ & $\begin{array}{l}\text { limit } \\
\text { limit }\end{array}$ \\
\hline MTH & $30-\mathrm{nm} \times 12-\mathrm{nm}(\mathrm{H} \times \mathrm{D})$ cylinder & $16 \mathrm{~nm}$ & $10^{\circ}$ & 0.2 & $60 \AA$ & $11 \mathrm{~nm}$ \\
Ribosome & $25-\mathrm{nm}$ diameter sphere & $30 \mathrm{~nm}$ & $\mathrm{n} / \mathrm{a}$ & 0.2 & $60 \AA$ & $30 \mathrm{~nm}$ \\
\hline
\end{tabular}

$\mathrm{CC}=$ cross-correlation. + Owing to the cylindrical symmetry of the reference used for the MTH segments, the angular search was not done around the cylindrical axis and was also limited to $\pm 90^{\circ}$ around the other two axes. No angular search was done for ribosomes because the reference had spherical symmetry. If two template matching hits were positioned within the overlap limit, they were considered duplicates and one was removed automatically in PEET. 
bioRxiv preprint doi: https://doi.org/10.1101/746982; this version posted May 2, 2021. The copyright holder for this preprint (which was not certified by peer review) is the author/funder, who has granted bioRxiv a license to display the preprint in perpetuity. It is made available under aCC-BY-NC-ND 4.0 International license.

\section{Supplemental references}

1 Ben-Shem, A. et al. The structure of the eukaryotic ribosome at 3.0 A resolution. Science 334, 1524-1529, doi:10.1126/science.1212642 (2011).

$2 \mathrm{Xu}$, L., Ajimura, M., Padmore, R., Klein, C. \& Kleckner, N. NDT80, a meiosis-specific gene required for exit from pachytene in Saccharomyces cerevisiae. Mol Cell Biol 15, 6572-6581 (1995).

3 Scherthan, H. et al. Chromosome mobility during meiotic prophase in Saccharomyces cerevisiae. Proc Natl Acad Sci U S A 104, 16934-16939, doi: 10.1073/pnas.0704860104 (2007).

4 White, E. J., Cowan, C., Cande, W. Z. \& Kaback, D. B. In vivo analysis of synaptonemal complex formation during yeast meiosis. Genetics 167, $51-63(2004)$. 